\title{
Oil price shocks and renewable energy transition: Empirical evidence from net oil-importing South Asian economies
}

\author{
Muntasir Murshed ${ }^{1}$ (D) $\cdot$ Muntaha Masud $\operatorname{Tanha}^{2}$ (I) \\ ${ }^{1}$ School of Business and Economics, North South University, Dhaka, Bangladesh \\ ${ }^{2}$ Department of Economics, East West University, Dhaka, Bangladesh
}

Received: 12 February 2020/Revised: 5 May 2020/Accepted: 9 May 2020/Published online: 21 May 2020

(C) The Joint Center on Global Change and Earth System Science of the University of Maryland and Beijing Normal University 2020

\begin{abstract}
This paper makes a novel attempt to model the nonlinear association between renewable energy consumption and crude oil prices concerning four net oil-importing South Asian economies: Bangladesh, India, Pakistan and Sri Lanka. Using annual data from 1990 to 2018, the long-run elasticity estimates confirm the nonlinear nexus and suggest that although rising crude oil prices do not facilitate renewable energy consumption initially, upon reaching a threshold level of crude oil price, further hikes in the oil prices are likely to elevate the renewable energy consumption figures. The estimated real oil price threshold, in this regard, is predicted to be around 135 US dollars per barrel, which is way above the prevailing oil price level. Identical nonlinearity is also confirmed in the context of the oil prices and renewable energy share in total final energy consumption volumes. Moreover, the nexus between renewable electricity share in aggregate electricity outputs and crude oil prices is also seen to exhibit nonlinearity. However, rising crude oil prices were not found to enhance the renewable electricity shares. Besides, the causality results implicated that movements in crude oil prices influenced the renewable energy transition process across the concerned South Asian economies. Thus, these results, in a nutshell, impose critically important policy implications for attainment of energy security and environmental sustainability in South Asia, particularly via curbing the traditional imported crude oil-dependencies of these nations.
\end{abstract}

Muntasir Murshed

muntasir.murshed@northsouth.edu
Keywords Renewable energy - Crude oil price ·

Renewable energy transition $\cdot$ South Asia $\cdot$ Cross-sectional dependency $\cdot$ Net oil-importing economies

JEL Classification F64 - O13 $\cdot$ P18 $\cdot$ P28 $\cdot$ Q4 $\cdot$ Q43

\section{Introduction}

Deteriorating environmental quality and aggravating climate change adversities worldwide have cumulatively sparked the consensus in aligning the global development policies with simultaneous safeguarding of the environmental attributes as well. In the past there had been an agreement to the concept of 'growing the economy now and cleaning up the environment later,' thus, accepting the trade-off between economic and environmental welfares. However, the contemporary development policies tend to primarily focus on greening of the global production processes, particularly to curb the greenhouse emissions that stem from the predominant combustion of fossil fuels. Therefore, it is pertinent for the world economy to undergo a transition from use of non-renewable to renewable energy resources, keeping environmental sustainability into cognizance (Murshed 2018). In the same vein, the sustainable development goals (SDG) agenda of the United Nations has also called out for worldwide commitments to augment renewable energy (RE) resources into the global energy-mixes for ensuring energy security and environmental sustainability across the planet. The 7th of the seventeen SDG specifically stresses for substantially elevating the shares of renewables in the global energy consumption figures by the end of 2030 (Villavicencio Calzadilla and Mauger 2018). Therefore, the world 
economies have expressed their commitments with respect to the attainment the SDG within this stipulated time frame.

The benefits of enhancing the volumes of renewable energy consumption (REC) within the economy can embody multidimensional forms. For instance, incorporating RE technologies into the national energy policies worldwide is likely to complement the global energy security strategies which seem to be at risk due to the depletion of the global non-renewable energy (NRE) reserves (Valentine 2011). Thus, augmentation of RE into the global energy-mixes would not only relieve pressures off the world demand for fossil fuels, but it would also complement the NRE in significantly improving the overall reliability of energy supplies (Zemin 2008). Besides, REC can also exhibit a pivotal role in curbing the intensities of greenhouse emissions, therefore, attributing to improvements in the environmental quality while slowing down the climate change phenomenon in tandem (Perry et al. 2008). Boosting the consumption levels of RE has also been appropriately acknowledged in the 2015 Paris climate change conference to play a defining role in keeping the global temperature rise below the critical level of $2{ }^{\circ} \mathrm{C}$ per annum which is pertinent in combating the climate change adversities to a large extent. ${ }^{1}$ Among the other positive impacts, REC is hypothesized to reduce the vulnerability of economies against the exogenous volatility of crude oil supplies (Rentschler 2013), stabilize energy prices (Shen et al. 2010), enhance energy-use efficiency levels (Murshed 2019), expand electricity-access rates (Oseni 2012), attribute to rural electrification (Urmee et al. 2009), facilitate off-grid electrification (Sen and Bhattacharyya 2014) and also create job opportunities within the local community (Sari et al. 2008; Llera et al. 2013).

However, despite such advantageous features, the adoption of RE technologies is not so straightforward due to the generation, storage and transmission of both primary and secondary RE sources being overwhelmingly conditional on the availability of the appropriate technology (Painuly 2001). Thus, technological redundancy, within the developing economies in particular, often upholds the substitution of fossil fuels via renewable alternatives. Besides, the underdeveloped energy infrastructure within these nations is also proclaimed to be one of the major hindrances bottlenecking their prospects of undergoing the renewable energy transition (RET) phenomenon (Murshed 2020). More importantly, implementation of the RET policies is relatively difficult in the context of net oil-importing countries (NOIC) courtesy of their acute vulnerability to exogenous shocks to the world crude oil prices (Gupta 2008). A particular reason behind this could be interpreted in terms of the predominant reliance of

\footnotetext{
${ }^{1}$ For more information on the Paris climate change Conference of Parties21 (COP21) see Rhodes (2016) and Robbins (2016).
}

these nations on crude oil imports, mostly for domestic power generation purposes. In addition, inadequate natural RE endowments often compel these nations to rely on imported oils as well. Consequently, such monotonic fuel-dependency often restrains these economies from switching to RE use; thus, attributing to the adverse environmental complications stemming from the obligatory combustion of the imported oils. Besides, these economies are also referred to be highly susceptible to other multifaceted macroeconomic adversities, following the impulsive movements in world crude oil prices, as well (Cunado et al. 2015).

Moreover, the relatively higher startup costs of setting up the RE power plants, solar in particular, have also accounted for high renewable electricity prices within the NOIC, thus, deterring the RET phenomenon further. In comparison to the traditional oil-based power prices, the prices of electricity sourced from solar and wind energy in Britain are higher by more than two times (The Economist 2014). Moreover, the ideal locations of the renewable power plants are usually across regions far away from the cities which further inflate the associated power transmission and distribution costs. However, in recent times, the average cost of RE production has gone down to a large extent. According to a report by the International Renewable Energy Agency (IRENA 2019), the global weighted-average costs of solar power, between 2010 and 2018, have significantly declined to almost match the corresponding costs of generating electricity from the fossil fuels, oils in particular. More importantly, upon analyzing the levelized cost of energy $(\mathrm{LCOE})^{2}$ in the context of electric power generated from both renewable and non-renewable sources, it is evident that renewable power prices have substantially reduced over time. For instance, within South Asia and the Pacific, the LCOE produced using solar power declined the most from being around 350 US dollars per megawatt in 2010 to 69 US dollars per megawatt by the end of 2019 while the LCOE for natural gas-fired electricity remained fairly stagnated at around 72 US dollar per megawatt (Harder 2019, August 1). Moreover, among the Asia Pacific economies, India currently accounts for the lowest cost of RE production whereby the nation's solar LCOE has dropped below the LCOE for power generated from coal (Wood Mackenzie 2019). Hence, taking the lower costs of $\mathrm{RE}$ generation, in recent times, into consideration, undergoing RET across the NOIC, in particular, can be expected to be a crucial energy policy intervention in simultaneously ensuring energy and environmental sustainability.

Against this background, this paper aims to probe into the dynamic impacts of world crude oil price shocks on the RET process across four major NOIC across South Asia namely Bangladesh, India, Pakistan and Sri Lanka. The fact that all these nations have traditionally been vastly reliant on crude oil imports, investigation of the cross-price

\footnotetext{
${ }^{2}$ For more information on the LCOE see IRENA (2019)
} 
elasticity of RE demand becomes a pertinent topic of research, keeping South Asia's prospects of RET into consideration. Although existing studies have probed into the impacts of oil prices on REC using a linear framework, in the context of South Asia, the possible nonlinearity of the REC-crude oil price nexus is yet to be explored. It is germane to address the quadratic association between these variables from the notion that oil price movements may not be able to induce RET instantaneously, following the inability to undergo RET due to being a large share of their national outputs being generated using power sourced from the imported crude oils. Thus, REC in the initial stages can be expected to pretty inelastic to rising crude oil prices in the world market. However, alongside substantial economic development of these economies with time, the barriers to RE adoption could be expected to reduce whereby the elasticity of REC concerning further hikes in crude oil prices could be anticipated to improve to facilitate the RET process. This paper contributes to the literature in this regard by modeling the nonlinear association between REC and movements in the prices of crude oil. Addressing this nonlinearity is of relative significance in the context of NOIC since these economies are highly rigid to RET in the short-run following their extensive reliance on imported crude oils.

On the other hand, power prices have progressively gone up in the selected South Asian NOIC as well. Although such price hikes could partially be attributed to the overall growth of these economies, exerting demand-induced inflationary pressures on the electricity prices, the volatility of oil prices in the world market (Yasmeen et al. 2019) and acute shortages of the primary energy resources (Shakeel et al. 2016) have collectively driven up the price of electricity. In Bangladesh, the flat rate of electricity provided to the small industries increased from 4.02 Bangladeshi Takas per kilowatt-hour in 2007 to almost 8.20 Bangladeshi Takas per kilowatt-hour by the end of 2017 (BPDB 2017). Similar upward trends are also seen for prices of the residential, commercial, industrial electricity supplies. Likewise, the wholesale electricity price index of India surged from 102.40 in 2013 to 108.70 by the end of 2018, depicting a $6.15 \%$ growth in the electricity prices during the aforementioned period (OEA 2020). Moreover, between 2010 and 2014, the nation's agriculture, residential, industrial and commercial electricity price indices on average grew by $66 \%, 30 \%, 17 \%$ and $14 \%$, respectively (OEA 2020). Similar trends are also evident in the context of Pakistan where the government has persistently raised the electricity prices to account for fuel cost adjustments (Times of Islamabad 2019, December 26). In contrast, average electricity prices in Sri Lanka have recently exhibited declining trends (Climatoscope 2019) which can plausibly be attributed to the nation's relatively less oil- dependency for electricity generation purposes among the selected South Asian NOIC. Hence, keeping the trends in low LCOE for renewable electricity production and the surging electricity prices in the majority of these economies into consideration, reducing oil-dependency could be ideal in limiting electricity prices while safeguarding the environment via facilitating the RET phenomenon across South Asia.

This paper specifically addresses the following questions in the context of the selected South Asian NOIC:

1. Is the relationship between REC and crude oil prices nonlinear?

2. Do exogenous shocks to crude oil prices facilitate the RET phenomenon?

3. Does imported oil-dependency hamper the prospects of switching from NRE to RE use?

4. Is there any causality between crude oil price movements and consumption of RE?

The remainder of the paper is organized as follows. Section 2 provides an overview of the state of RE use within the four South Asian NOIC. A review of the relevant theoretical and empirical literature is put forward in Sect. 3. Section 4 presents the empirical model and chalks down the attributes of the dataset used. The methodological approach is explained in Sect. 5, while Sect. 6 discusses the findings from the econometric analyses. Finally, Sect. 7 concludes and highlights the potential policy implications.

\section{An overview of the trends in REC across South Asia}

Apart from belonging to the lower-middle-income group and being net importers of crude oil, all these four South Asian economies have traditionally sourced a significant proportion of their respective national outputs using NRE resources, imported crude oils in particular. Table 1 depicts the trends in REC between 1990 and 2018. As far as the employment of RE is concerned, Sri Lanka can be seen to head the list in terms of recording the highest per capita REC figures among the four South Asian economies. A particular reason behind this phenomenon could be attributed to the nation's indigenous biomass energy resources accounting for a dominant share of the aggregate primary energy consumption figures (Nissanka and Konaris 2010). In contrast, Bangladesh accounts for the lowest per capita REC levels. This can fundamentally be credited to the nation's insufficient natural endowments of primary RE supplies. Between 1990 and 2018, the per capita REC, in terms of kilograms of oil equivalent, in India and Sri Lanka rose on average by $8.33 \%$ and $18.91 \%$, respectively, while that in Bangladesh and Pakistan declined, respectively, by 
Table 1 Trends in REC across the selected South Asian economies. Source: World Development Indicators (World Bank 2019)

\begin{tabular}{|c|c|c|c|c|}
\hline Period & Bangladesh & India & Pakistan & Sri Lanka \\
\hline \multicolumn{5}{|c|}{ Renewable energy consumption ( $\mathrm{kg}$ of oil equivalent per capita) } \\
\hline $1990-1995$ & 88.40 & 207.13 & 229.73 & 241.54 \\
\hline 1996-2000 & 84.62 & 211.68 & 228.33 & 253.90 \\
\hline 2001-2005 & 84.10 & 216.26 & 225.57 & 273.60 \\
\hline 2006-2010 & 84.70 & 221.26 & 221.76 & 286.26 \\
\hline $2011-2015$ & 83.53 & 226.48 & 216.33 & 300.00 \\
\hline 2016-2018 & 83.00 & 224.37 & 216.73 & 287.21 \\
\hline \multicolumn{5}{|c|}{ Renewable energy share ( $\%$ of total energy consumption) } \\
\hline $1990-1995$ & 69.97 & 56.75 & 55.51 & 74.34 \\
\hline $1996-2000$ & 60.37 & 52.45 & 51.38 & 64.37 \\
\hline $2001-2005$ & 53.13 & 50.30 & 49.43 & 61.60 \\
\hline 2006-2010 & 45.34 & 43.44 & 45.86 & 61.86 \\
\hline $2011-2015$ & 37.84 & 37.57 & 46.63 & 58.05 \\
\hline 2016-2018 & 37.11 & 36.96 & 46.75 & 55.89 \\
\hline
\end{tabular}

The figures are given in terms of period averages

$6.10 \%$ and $5.66 \%$. It is also evident from Table 1 that all these four nations have performed miserably in improving the RE shares in their respective total final energy consumption levels. The average RE share of Bangladesh has gone down by almost 33 percentage points followed by India, Sri Lanka and Pakistan registering declines in their respective RE shares by $19.79,18.45$ and 8.75 percentage points. These adverse trends seem to portray ominous signals concerning the attainment of RET across South Asia. Hence, it is critically important to identify the factors inhibiting the consumption of renewables from policy perspectives.

As far as the national fuel-mixes for electricity generation purposes are concerned, Fig. 4 in "Appendix" illustrates the trends in the renewable and non-renewable electricity outputs across the selected South Asian NOIC. It is apparent from the graphs that the shares of renewable electricity in aggregate electricity output levels of India, Pakistan and Sri Lanka have declined, on average, between 1990 and 2015. Similar downward trends revealed in the context of Bangladesh over the 2005-2015 period. Bangladesh accounts for the lowest renewable electricity output shares among the four South Asian economies which can largely be credited to the nation's predominant reliance on indigenous natural gas and imported oils for power generation purposes. In contrast, Sri Lanka has traditionally been the forerunner in terms of registering the highest renewable electricity output shares. However, the nation's renewable electricity share has remarkably dropped by a staggering 51.37 percentage points, on average, between 1990 and 2015, while its reliance on imported oils for power generation purposes has significantly escalated in tandem. On the other hand, Pakistan has gradually accentuated its reliance on imported oils as perceived from a rise in the nation's share of electricity from oil, in the aggregate electricity outputs, by almost 17 percentage points, on average, between 1990 and 2015. Figure 4 also portrays heterogeneity across these economies concerning their respective national energy-mixes. It is evident that a major proportion of total electricity in Bangladesh and Pakistan is sourced from the combustion of the indigenous natural gas supplies, while India banks heavily on its coal resources to generate electricity. On the other hand, Sri Lanka produces a significant amount of its electricity outputs from the RE resources. However, all these nations still import a significant amount of crude oil for producing electricity which seems to be one of the prime factors attributing to South Asia's environmental hardships.

Figure 1 depicts the correlative plots of RE shares in total energy consumption figures and real crude oil prices across the selected South Asian economies between 1990 and 2018. The inverted-U shapes of the fitted lines, as shown in Fig. 1, portray the dependence of these nations on crude oil imports since rising crude oil prices are initially accompanied by lower RE shares which, after a threshold level of oil price, elevates the RE shares. Hence, these interesting trends further stress on the need to investigate the potential nonlinearity of the REC-crude oil price nexus in the context of the South Asian NOIC. Moreover, Fig. 5 in "Appendix" plots the historical trends in the RE shares, renewable electricity output shares and real crude oil prices between 1990 and 2015. It is apparent from the statistical trends that a persistent rise in the real oil prices has dampened both the shares of RE consumption and renewable electricity outputs in most of the selected South Asian NOIC. Hence, these trends seem to further highlight the extent of oil dependency among these nations which makes it is difficult for these nations to completely switch from consumption of oil to the RE alternatives. Among the selected South Asian NOIC, Bangladesh is referred to as the most oil-vulnerable nation, while India is said to be least vulnerable to oil price shocks (Mohsin et al. 2018).

\section{Literature review}

This section is subdivided into two subsections in which the former discusses the theoretical framework engulfing the REC-crude oil prices nexus while the latter sheds light on the empirical evidence in this regard.

\subsection{Theoretical framework}

The impacts of exogenous shocks to world crude oil prices on REC can be explained using the concept of substitution 
Bangladesh

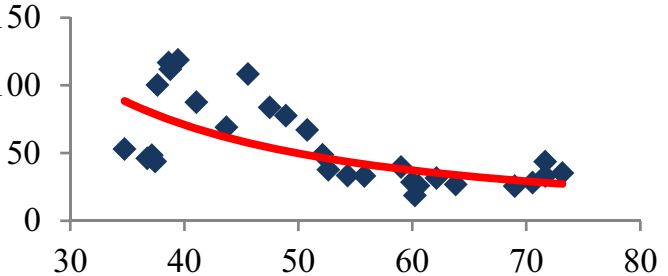

Pakistan

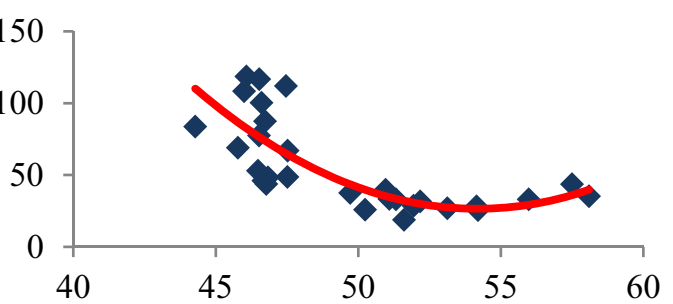

India

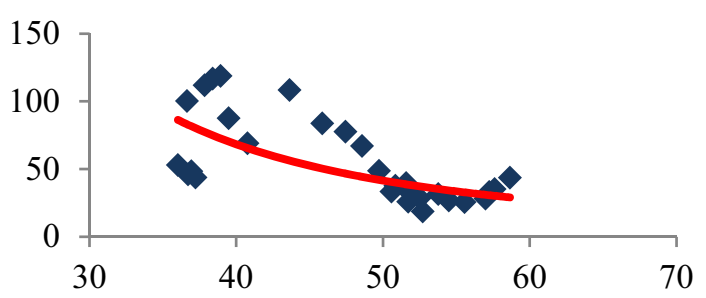

Sri Lanka

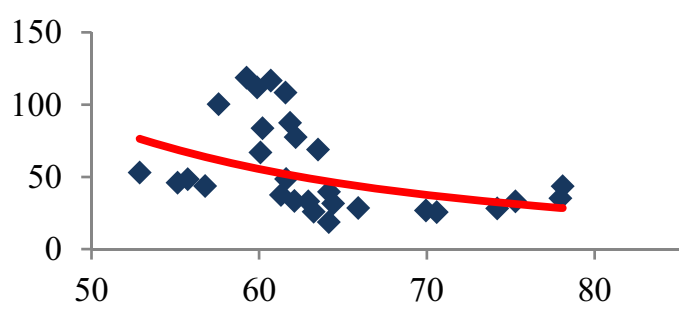

Crude Oil Price (2016 US\$ per barrel)

Fig. 1 Correlative plots of renewable energy shares and crude oil prices. Source: Author's own

effect (SE) of a price change. ${ }^{3}$ Usually, the total impact of a change in the price of a commodity can be expressed as a sum of the substitution and income effects. However, this paper confines the discussion to explaining the REC-oil price nexus using the SE stemming from a rise in crude oil prices. Several studies have referred to RE resources as substitutes for the NRE resources such as crude oil, coal and natural gas (Kruger 2006). Hence, assuming RE resources as a perfect substitute for fossil fuels, a rise in world crude oil prices is likely to induce a SE whereby the volume of REC can be anticipated to go up. Figure 2 illustrates the dynamics in this regard. Prior to the rise in the crude oil prices, across the world market, the optimum level of REC takes place at point A where the indifference curve (IC) is tangential to the slope of the budget constraint $\left(\mathrm{BC}_{0}\right)$. The slope of this budget constraint is given by the relative price ratio of RE resources and crude oil $\left(\mathrm{PRE}_{0} /\right.$ POIL $_{0}$ ). At point $\mathrm{A}$, the optimum levels of REC and oil consumption are, respectively, shown as $\mathrm{RE}_{0}$ and $\mathrm{OIL}_{0}$. Now assuming that the price of crude oil, which is determined in the world market, goes up (from POIL 0 to POIL $_{1}$ ) while the price of renewables, which is locally determined, is assumed to stay put (at $\mathrm{PRE}_{0}$ ). Hence, the relative price ratio would decline resulting in the slope of the budget constraint being flatter. The new budget constraint can be shown as $\mathrm{BC}_{1}$ and the corresponding relative price ratio is given by $\mathrm{PRE}_{0} / \mathrm{POIL}_{1}$. Under such circumstances, there will be a movement along the indifference curve, from

\footnotetext{
${ }^{3}$ For more information on substitution effects see Ashenfelter and Heckman (1974).
}

point A to point $\mathrm{B}$, whereby the consumption of renewables can be expected to rise while oil consumption is likely to decline. The SE of the rise in world crude oil prices can, therefore, be shown as the increase in the levels of REC from $\mathrm{RE}_{0}$ to $\mathrm{RE}_{1}$ and the decrease in oil consumption levels from $\mathrm{OIL}_{0}$ to $\mathrm{OIL}_{1}$.

However, this mechanism is strongly grounded on the assumption of RE resources and fossil fuels being perfect substitutes. In the case of these two variables not being perfect substitutes, the SE could be negligible whereby the impact of rising crude oil prices on the level of REC may not be as pronounced. Under more adverse scenarios, in which the RET is not possible due to certain macroeconomic limitations, particularly in the form of predominant oil-dependencies, rising crude oil prices may even foster higher consumption of crude oils to meet the aggravating demand for energy to produce the national outputs. As a consequence, the share of NRE in aggregate energy consumption levels can be anticipated to rise along with the rise in crude oil prices. Hence, it can be said that the exact nature of the RECcrude oil price nexus depends on the possibility of the substitution between the NRE and RE resources and also on the extent of crude oil-dependency of the concerned economy.

\subsection{Empirical evidence}

A plethora of studies have attempted to model the impacts of oil prices on the demand for RE in the context of both developed and developing economies. In a country-specific study by Sadorsky (2009), the author probed into the factors attributing to REC within the Group of Seven (G7) 


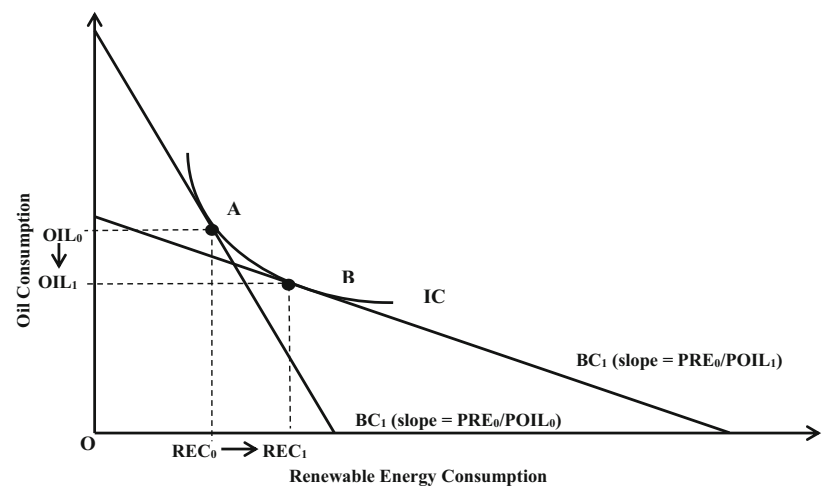

Fig. 2 The Substitution Effect of rising crude oil prices on energy consumption trends. Source: Authors' own

economies using annual data from 1980 to 2005 . The shortrun results from the error-correction model approach revealed that rising oil prices increased REC in France while reducing it in the context of the UK. However, no statistical short-run impact could be established for the rest of the G7 nations. The long-run findings, tapping the fully modified and dynamic ordinary least squares approach, showed that rising oil prices ultimately increased REC within France, Germany and Italy but led to declines in the REC levels in the context of Canada, Japan, the UK and the USA. However, the results also showed that REC is pretty elastic to changes in oil prices across Germany, the UK and the USA while for France, Italy, Canada and Japan evidence of an inelastic association between REC and oil price movements was ascertained. For the pooled data of all the G7 nations, a negative correlation between oil price and REC was also evidenced by the statistical significance of the long-run elasticity estimate.

Azad et al. (2014) used annual time-series data spanning across 1990 and 2011 to conduct simulation exercises for assessing the impacts of oil price shocks on Australia's RE demand. The results from the Generalized Method of Moments (GMM) regression approach provided statistical evidence regarding RE resources being substitutes for fossil fuels in the context of Australia. The corresponding elasticity estimate denoted that the marginal effect of a rise in the price of crude oil attributed to a rise in the volume of REC by $0.14 \%$, on average, ceteris paribus.

The causal linkage between REC and real oil prices for the USA, over the period 1949-2009, was estimated by Payne (2012). Results from the Toda-Yamamoto long-run causality approach suggested no causation between the two variables. Moreover, the impulse response function analyses revealed that unexpected shocks to real oil prices could not establish a statistically significant impact on the country's REC over a 10-year period. Instead, the statistical estimates revealed that REC in the USA responds positively to positive shocks to the country's real GDP and carbon emissions figures.

In a recent study by $\mathrm{Ji}$ and Zhang (2019), the factors affecting REC growth in China, between 1992 and 2013, were explored using variance decomposition techniques within a vector autoregressive (VAR) model framework. The corresponding results indicated that changes in crude oil prices accounted for almost $20 \%$ of the total variations in China's RE share in aggregate final energy consumption figures. Moreover, upon checking for the robustness of the findings using an alternate indicator of RE use within the Chinese economy, the findings revealed that oil prices explained almost one-fourth of the total variations in China's volumes of non-hydroelectric power. The overall results highlighted that the movements in oil prices were second to financial development in explaining the changes in the growth of the RE sector of China.

Shah et al. (2018) analyzed the impacts of oil price shocks and other macroeconomic aggregates on RE investment trends in Norway, the USA and the UK. The study utilized annual data stemming from 1960 to 2015 to perform the forecast error variance decomposition analysis within a VAR framework. The results showed that shocks to both real and nominal prices of oil failed to exert much impact on the trends in RE investments in the UK. In contrast, positive shocks to oil prices were found to trigger positive movements in the RE investment figures of Norway and the USA. The authors referred to state intervention in the UK as the core reason behind the ineffectiveness of oil price shocks to explain movements in the nation's RE investment trends. The causality estimates revealed that only in the context of the USA, a unidirectional causality was found to be stemming from oil prices and investment in the nation's RE sector. Furthermore, the authors concluded that the impacts of oil price shocks on the development of the RE sector depend on whether an economy is a net importer or a net exporter of oil. The fact that the USA was a net importer of oil across a lion's share of the study period was claimed to be the reason behind the nation's RE investment trends being responsive to oil price shocks.

Among the various cross-country examinations documented in the literature, Omri and Nguyen (2014) used annual data in the context of 64 global economies, from 1990 to 2011, to model the elasticity of REC with respect to changes in real prices of crude oil. Results from the dynamic system-GMM regression analyses revealed that rising crude oil prices reduced the volume of per capita REC across the entire panel of 64 countries. Moreover, up classifying the countries in terms of their respective income group, the regression estimates revealed that a rise in the real values of crude oil prices by $1 \%$ was accompanied by a reduction in the per capita REC figures for the panel of the 
middle-income economies by $0.34 \%$, on average, ceteris paribus. However, no statistically significant impact could be ascertained in the context of the low-income and the high-income panels. Thus, the authors opined in favor of the heterogeneity of the REC-oil price nexus across economies concerning the income group they belong to.

The REC-oil price nexus in the context of seven Central American nations was explored by Apergis and Payne (2014a). The authors used annual data for all the seven economies over the period 1980-2010. The regression analysis was conducted using the fully modified ordinary least squares estimator. The elasticity estimates showed that the per capita REC within the selected Central American economies responded to changes in both real prices of oil and coal. In particular, a $1 \%$ rise in the real oil prices was found to elevate the per capita REC figures by $0.29 \%$, on average, ceteris paribus, thus, implicating the substitutive properties between RE and fossil fuels in the context of the selected nations. Moreover, the authors also concluded that real oil prices, over the entire study period, do not exert a causal impact of the per capita REC figures. However, allowing for regime shifts in the year 2002, the causality findings during the pre-2002 period revealed statistical evidence regarding unidirectional short-run causal impacts of real oil prices on per capita REC while in the long-run bidirectional causation between the variables was observed. On the other hand, in the post-2002 period, bidirectional causalities between real oil prices and REC per capita were found in both the short- and the long-runs.

Marques and Fuinhas (2011) assessed the drivers of RE use across 24 European Union nations between 1990 and 2006. The uniqueness of this study involved the consideration of prices of disaggregated NRE resources to estimate their conditional impacts on the demand for RE. The regression results from the difference-GMM, system-GMM and the least squares dummy variable correlated estimators unanimously suggested that oil prices are statistically insignificant in explaining the changes in the shares of renewable in the total energy consumption figures of the European Union member countries. In a similar study, Damette and Marques (2019) also probed into the drivers of REC within the 24 European Union nations. Upon controlling for the problem of dependencies across the cross-sections, the authors employed the pooled mean group panel data estimator to deduce the long-run elasticities. The results showed that oil prices exhibited a positive and statistically significant impact on the share of renewables in total energy production levels. Moreover, the authors also opined that rising dependency on energy imports also contributed to higher RE shares in total energy supplies.

The dynamics engulfing the REC-oil price nexus in the context of 25 member states under the Organization for
Economic Co-operation and Development (OECD) were examined by Apergis and Payne (2014b). The study employed annual data from 1980 to 2011 to predict the long-run associations. The results advocated in favor of the long-run cointegrating associations between per capita REC and real oil prices. Moreover, the long-run elasticity between these variables, as predicted using the panel fully modified ordinary least squares estimator, showed that the marginal impact of a rise in real oil prices triggered a simultaneous increase in the per capita REC figures by $0.45 \%$, on average, ceteris paribus. Moreover, the causality estimates from the panel error-correction method revealed a bidirectional causal association between per capita REC and real oil price both in the short- and long-runs.

In a similar study, Apergis and Payne (2015) employed panel cointegration techniques to predict the long-run determinants of REC in the context of 11 South American nations, using yearly data between 1980 and 2010. The results from the fully modified ordinary least square technique indicated that REC per capita is positively influenced by rising real oil prices, thus, referring to RE resources as alternative sources of energy to fossil fuels. A $1 \%$ rise in the real price of oil was found to be accompanied by a $0.37 \%$ escalation in the per capita REC figures, on average ceteris paribus. Hence, these findings suggested that REC in the context of the concerned South American economies is inelastic to changes in world oil prices. Moreover, the causality estimates from the vector error-correction model approach discovered bidirectional short-run causation between per capita REC and real oil prices. However, in the long-run real oil price was found to causally impact the per capita REC figures without the feedback.

Hence, it is apparent from the equivocal conclusions made in the aforementioned country-specific and crosscountry empirical studies that rising crude oil prices do not guarantee the replacement of fossil fuel consumption via the RE alternatives. Moreover, considering country-specific features, a great deal of heterogeneity concerning the nature of the REC-oil price nexus is also evident. More importantly, the existing literature has overlooked the possible nonlinearity between these variables which could be effective in reasoning the ineffectiveness of higher crude oil prices in instigating the RET phenomenon, particularly from the perspectives of the NOIC. This paper attempts to address this gap in the literature by modeling the REC-crude oil price relationship in a nonlinear framework in the context of the four NOIC across South Asia. 


\section{Empirical model and data}

The selection of the empirical models is based on the underlying economic theories. To model the possible nonlinear association between crude oil prices and consumption of RE resources across the selected South Asian nations, the level of REC within the concerned economies is expressed as a quadratic function of real crude oil prices and controlled for key macroeconomic aggregates that may affect the overall nature of the REC-crude oil price nexus. The corresponding empirical model can be specified as:

$$
\begin{aligned}
\ln \mathrm{REC}_{i t}= & \beta_{0}+\beta_{1} \ln \mathrm{ROILP}_{i t}+\beta_{2} \ln \mathrm{ROILP}_{i t}^{2} \\
& +\beta_{3} \ln \mathrm{RGDP}_{i t}+\beta_{4} \ln \mathrm{RGDP}^{2} \ln \mathrm{ROILP}_{i t} \\
& +\beta_{5} \mathrm{DEPEND}_{i t}+\beta_{6} \ln \mathrm{CO}_{2 i t}+\beta_{7} \ln \mathrm{TO}_{i t}+\varepsilon_{i t}
\end{aligned}
$$

where the subscripts $i$ and $t$, respectively, denote the individual cross-sectional units and the time period. $\beta_{i}$ $(i=1, \ldots, 7)$ are the elasticity parameters to be estimated while $\varepsilon$ is the error-term. The variable REC is per capita consumption of RE, measured in terms of kilograms of oil equivalent. ROILP and ROILP ${ }^{2}$ stand for the real prices of crude oil and its squared term, respectively. The unit of measurement of real crude oil prices is in terms of US dollars per barrel in constant 2016 prices. It is worth noting that the statistical significance of the elasticity parameters attached to ROILP and ROILP ${ }^{2}$ would portray a nonlinear association between REC and real crude oil prices in the context of the selected South Asian nations.

Among the other key variables controlling the econometric framework, RGDP abbreviates for the real gross domestic product which is included to account for the possible effects of economic growth on the facilitation of REC across the concerned economies. Economic growth can be anticipated to exert a positive impact on the REC figures via empowering the concerned nations to overcome the limitations restraining the RET phenomenon (Murshed 2020). Also, RGDP is interacted with ROILP and included in the model to account for the joint impacts of economic growth and crude oil price shocks on the movements in the REC levels. The rationale behind the inclusion of this interaction term could be explained in the sense that as an economy, particularly the one that is a net importer of crude oil, experiences growth it can gradually lessen its dependence on the oil imports which, in turn, can be expected to elevate its REC levels. In the same vein, the econometric model is also controlled for the imported oil-dependency, abbreviated by DEPEND, within the selected South Asian economies. Following Damette and Marques (2019), imported oil-dependency is proxied by the share of energy imports in the total merchandize imports figures of the respective economies. A rise in the share of energy imports in aggregate merchandise import figures can be interpreted as a simultaneous increment in the degree of oil-dependency which, in turn, can be associated with lower REC within the economies.

Besides, the econometric model is also controlled for carbon-dioxide emissions. The variable $\mathrm{CO}_{2}$ stands for the volume of carbon-dioxide emissions measured in terms of $\mathrm{kg}$ per 2010 US dollars' worth of GDP. It is pertinent to include carbon-dioxide emissions in modeling the trends in REC since rising apprehensions regarding the air-pollution induced climate change adversities are likely to facilitate the substitution effect between the consumption of fossil fuels and the renewable alternatives (Omri and Nguyen 2014). Finally, TO denotes the trade openness index, measured in terms of the sum of imports and exports as a percentage of the GDP. The relevance of considering openness to trade for modeling the REC trends can be justified in the sense that a rise in the trade openness indices can be interpreted as a reduction in the trade barriers which can be anticipated to facilitate cross-border flows of renewable power, thus, boosting the REC levels (Murshed 2018).

For the robustness check of the REC-crude oil price nexus, model (1) is re-estimated using two alternate indicators of REC, namely the share of renewables in total final energy consumption figures and the share of renewable electricity in aggregate electricity output levels. The corresponding models can be specified as:

$$
\begin{aligned}
\ln \mathrm{RES}_{i t}= & \alpha_{0}+\alpha_{1} \ln \mathrm{ROILP}_{i t}+\alpha_{2} \ln \mathrm{ROILP}_{i t}^{2} \\
& +\alpha_{3} \ln \mathrm{RGDP}_{i t}+\alpha_{4} \ln \mathrm{RGDP} \\
& * \ln \mathrm{ROILP}_{i t}+\alpha_{5} \mathrm{DEPEND}_{i t}+\alpha_{6} \ln \mathrm{CO}_{2 i t} \\
& +\alpha_{7} \ln \mathrm{TO}_{i t}+\varepsilon_{i t}
\end{aligned}
$$

$$
\begin{aligned}
\ln \operatorname{RELEC}_{i t}= & \delta_{0}+\delta_{1} \operatorname{lnROILP}_{i t}+\delta_{2} \ln \mathrm{ROILP}_{i t}^{2} \\
& +\delta_{3} \ln \mathrm{RGDP}_{i t}+\delta_{4} \ln \mathrm{RGDP} * \ln \mathrm{ROILP}_{i t} \\
& +\delta_{5} \mathrm{DEPEND}_{i t}+\delta_{6} \ln _{2 \mathrm{CO}_{2 i t}}+\delta_{7} \operatorname{lnTO}_{i t}+\varepsilon_{i t}
\end{aligned}
$$

where RES and RELEC stand for the shares of renewable energy and renewable electricity, respectively, in the total final energy consumption and aggregate electricity outputs. All the variables have been transformed into their natural logarithms for the ease of the long-run elasticity estimation and also to minimize the sharpness of the annual data series to generate consistent and reliable estimates. The time frame of the dataset used in this paper stretches from 1990 to 2018. The real crude oil price data is sourced from British Petroleum's Statistical Review of World Energy 2019 (British Petroleum 2019) while data for all the other 
variables are retrieved from the World Development Indicators website of the World Bank (2019). Table 6 in "Appendix" provides the descriptive statistics of all the variables considered in the econometric analyses.

\section{Methodology}

The econometric analyses begin with the cross-sectional dependency (CD) analysis. The problem of CD is claimed to generate biased and inconsistent stationarity and cointegrating properties (Dong et al. 2018). Thus it is pertinent to investigate whether the panel series in the dataset are independent or not. CD usually stems from spatial effects whereby a particular economic data of two or more economies exert an impact on one another, thus, the associating the countries globally or regionally (Chudik and Pesaran 2013). This paper primarily employs the Breusch and Pagan (1980) Lagrange multiplier (LM) test to identify the possible CD issues in the panel data series. The LM test statistic can be specified as:

$\mathrm{LM}=\sum_{i=1}^{N-1} \sum_{j=i+1}^{N} T_{i j} \hat{\rho}_{i j}^{2} \rightarrow \chi^{2} \frac{N(N-1)}{2}$

where $N$ is the number of countries, $T$ is the time period and $\hat{\rho}_{i j}^{2}$ is the predicted correlation coefficient sourced from the residuals of the econometric model. Besides, the Pesaran (2004) CD test, ideally suited for handling datasets with small cross-sections and short time dimensions, is also employed. The Pesaran CD test statistic can be specified as:

$\mathrm{CD}=\sqrt{\frac{2}{N(N-1)}} \sum_{i=1}^{N-1} \sum_{j=i+1}^{N} T_{i j} \hat{\rho}_{i j}^{2} \rightarrow N(0,1)$

Both these test statistics are, respectively, estimated under the null hypothesis of cross-sectional independence against the alternative hypothesis of $\mathrm{CD}$. The results from the $\mathrm{CD}$ analyses for all three models are displayed in Table 7 in "Appendix". The statistical significances of the Breusch-Pagan LM and the Pesaran CD test statistics reject the null hypothesis of cross-sectional independence, for the respective models, to validate the existence of the $\mathrm{CD}$ among the panel series. Hence, the application of the conventionally used first-generation panel unit root and cointegration techniques is no longer valid since these methods fail to account for the CD issues in the dataset.

In addition to $C D$ analyses, it is pertinent to check the slope heterogeneity issue as well since ignoring the possible heterogeneity of the slope coefficients across the cross-sections could result in the estimations being biased. Thus, this paper uses the slope heterogeneity test proposed by Pesaran and Yamagata (2008) which estimates two test statistics, $\tilde{\Delta}$ and $\tilde{\Delta}_{\text {adj }}$, under the null hypothesis of slope homogeneity against the alternative hypothesis of slope heterogeneity. The corresponding results from the slope heterogeneity test, for models (1), (2) and (3), are reported in Table 7 in "Appendix". The statistical significance of the test statistics, at $1 \%$ level, rejects the null hypothesis to suggest the slope heterogeneity issues.

\subsection{Second generation panel unit root analysis}

The second generation panel unit root techniques are claimed to generate estimates via addressing the $\mathrm{CD}$ issues, much unlike the conventionally used first-generation panel unit root tests that assume cross-sectional independence. Thus, upon confirmation of the CD problem, the second generation panel unit root tests are employed. This paper uses the Cross-sectionally Augmented Dickey-Fuller (CADF) and the Cross-sectionally Augmented Im, Pesaran and Shin (CIPS) panel unit root estimation techniques proposed by Pesaran (2007). The CADF test statistic can be obtained from the generalized regression given below:

$$
\begin{aligned}
\Delta y_{i t}= & a_{i}+b_{i} y_{i, t-1}+c_{i} \bar{y}_{t-1}+\sum_{j=0}^{s} d_{i j} \Delta \bar{y}_{t-j}+\sum_{j=1}^{s} \delta_{i j} \Delta \bar{y}_{i, t-j} \\
& +e_{i t}
\end{aligned}
$$

where $\bar{y}$ and $\Delta \bar{y}$ are the cross-sectional averages of lagged levels and first differences, respectively, at time $T$ for all cross-sections. The estimated $t$ statistic from Eq. (6) is then used to compute the CIPS statistic which can be specified as:

$\mathrm{CIPS}=N^{-1} \sum_{i=1}^{N} \mathrm{CADF}_{i}$

where $\mathrm{CADF}_{\mathrm{i}}$ is the $t$ statistic estimated from the CADF regression model shown in Eq. (6). Both the CADF and CIPS tests are performed under the null hypothesis of nonstationarity of the respective variable against the alternative hypothesis of stationarity.

\subsection{Second generation panel cointegration analysis}

The popularly used panel cointegration methods namely the Pedroni (1999) residual-based cointegration technique does not take the $\mathrm{CD}$ among the panels into account. Thus, the Westerlund (2007) panel cointegration analysis, which is robust to handling cross-sectionally dependent panel datasets, is employed to investigate the long-run associations between the concerned variables included in the econometric models. The CD is accounted for under the Westerlund (2007) cointegration approach via estimation of the probability values of the test statistics using 
bootstrapping methods. A total of two group-mean tests and two panel tests are performed under the null hypothesis of no cointegration against the alternative hypothesis of cointegration among at least one cross-sectional unit or cointegration among the whole panel, respectively. The four tests under the Westerlund (2007) panel cointegration approach are structured in the context of an error-correction model which can be expressed as:

$$
\begin{aligned}
\Delta y_{i t}= & \delta_{i}^{\prime} d_{t}+\alpha_{i}\left(y_{i, t-1}-\beta_{i}^{\prime} x_{i, t-1}\right)+\sum_{j=1}^{p_{i}} \alpha_{i j} \Delta y_{i, t-j} \\
& +\sum_{-q_{i}}^{p_{i}} \gamma_{i j} \Delta x_{i, t-j}+e_{i t}
\end{aligned}
$$

where $d_{t}$ stands for the deterministic components and $p_{i}$ and $q_{i}$ are the lag lengths and lead orders which are allowed to vary across individual cross-sections. The two group-mean test statistics $G_{t}$ and $G_{a}$ and the two panel test statistics $P_{t}$ and $P_{a}$ within the Westerlund (2007) cointegration analysis can be specified as:

$G_{t}=\frac{1}{N} \sum_{i=1}^{N} \frac{\hat{\alpha}_{i}}{\operatorname{SE}\left(\hat{\alpha}_{i}\right)}$

$G_{a}=\frac{1}{N} \sum_{i=1}^{N} \frac{T \hat{\alpha}_{i}}{\hat{\alpha}_{i}(1)}$

$P_{t}=\frac{\hat{\alpha}_{i}}{\operatorname{SE}\left(\hat{\alpha}_{i}\right)}$

$P_{a}=T \hat{\alpha}_{i}$

The statistical significance of these test statistics rejects the null hypothesis to suggest long-run associations between the variables included in the model. The presence of cointegrating relationships is a pre-requisite to estimating the long-run estimates using appropriate regression methods.

\subsection{Panel regression analysis}

The presence of $\mathrm{CD}$ issues in the dataset is likely to be translated into misspecification problems resulting in biased regression outputs (Damette and Marques 2019). Similarly, the slope heterogeneity issues are also likely to generate similar problems as well (Pesaran and Yamagata 2008). Although the conventionally used panel data estimation techniques namely the fully modified ordinary least squares (FMOLS) and dynamic ordinary least squares (DOLS) are claimed to be able to handle the cross-sectional correlations among the panels, such methods overlook the slope heterogeneity issues by inappropriately assuming the existence of the homogeneous slope coefficients across all the cross-sections. To account for this problem, this paper uses three panel data regression estimators which, in addition to handling the $\mathrm{CD}$ issues, allow for the slope coefficients to vary across the cross-sectional units (Damette and Marques 2019).

The first of the three panel data regression techniques used in this paper is referred to as the mean group (MG) estimator developed by Pesaran and Smith (1995). The MG estimation primarily involves the estimation of the slope coefficients for each of the cross-sections, within the panel dataset, using the ordinary least squares (OLS) method and then averaging them across the panel units. This allows for the possible heterogeneity of the slope coefficients across the different cross-sections to overcome the inefficiencies of the FMOLS and the DOLS techniques. The MG estimator can be specified as:

$\hat{\beta}_{\mathrm{MG}}=N^{-1} \sum_{i=1}^{N} \hat{\beta}_{i}$

where $\hat{\beta}_{\mathrm{MG}}$ is the simple mean of the individual slope estimators from each cross-sectional unit. However, a major limitation of this technique is that it fails to account for the $\mathrm{CD}$ in the data. Thus, the common correlated effects mean group (CCEMG) estimator, proposed by Pesaran (2006), is tapped which is a cross-sectionally augmented version of the MG estimator to handle the $\mathrm{CD}$ issues as well. The CCEMG corrects the limitations of the $\mathrm{MG}$ estimator by incorporating the time-variant unobserved common factors stemming from the $\mathrm{CD}$ issues into the estimation process via augmenting these unobserved common factors into the regression model before estimating the individual slope coefficients for each of the crosssections and then averaging them across the panel units. Likewise the MG estimator, the CCEMG estimator can also be specified as:

$\hat{\beta}_{\mathrm{CCEMG}}=N^{-1} \sum_{i=1}^{N} \hat{\beta}_{i}$

where $\hat{\beta}_{\text {CCEMG }}$ is once again the mean of the individual slope estimates from each cross-sectional unit. The only difference between the MG and the CCEMG estimators, respectively, expressed in Eqs. (13) and (14), is that the CCEMG estimator estimates and averages the individual slope coefficients via augmenting the common factors across the cross-sections into the empirical model which is not the case in the context the MG estimator.

Finally, for the robustness check, the augmented mean group (AMG) estimator proposed by Bond and Eberhardt (2013) is used for the regression analyses. The AMG estimator, much like the CCEMG estimator, also allows for slope heterogeneity and $\mathrm{CD}$ issues in the data. However, the AMG estimator augments the year dummies into the model and refers the time-variant unobserved common 
factors to exhibit a dynamic process whereas the CCEMG estimator includes the unobserved common factors in the error term (Mrabet et al. 2019).

\subsection{Heterogeneous panel causality analysis}

Finally, the causality analyses are performed to understand the pairwise causal dynamics between the variables of concern. The newly developed Dumitrescu-Hurlin (DH) panel causality estimation technique developed by Dumitrescu and Hurlin (2012) is applied in this paper. Application of the conventionally used Granger (1969) causality test is inappropriate following the slope heterogeneity issues in the data since this technique assumes the slopes to be homogeneous across the cross-sectional units. The Granger (1969) causality test statistic is estimated under the null hypothesis that causality does not exist between a pair of stationary variables belonging to all the cross-sections, against the alternative hypothesis of causality existing between these variables homogenously across all the cross-sections. In contrast, the DH causality technique allows for heterogeneity across the cross-sections to estimate the $z$-bar statistics using the null hypothesis that causality does not exist between a pair of stationary variables in all the cross-sections, referred to as the homogenous non-causality (HNC) null hypothesis, against the nonhomogenous alternative hypothesis of causality existing between these variables in at least one of the cross-sections. The mean statistic used to test the HNC null hypothesis can be specified as:

$W_{N, T}^{\mathrm{HNC}}=\frac{1}{N} \sum_{i=1}^{N} W_{i, T}$

where $W_{N, T}^{\mathrm{HNC}}$ is the mean value of the individual Wald statistics $W_{i, t}$. According to Dumitrescu and Hurlin (2012), under the assumption that the individual residuals are independently distributed across all the cross-sections and their covariances are equal to zero, the mean statistic sequentially converges to the equation below when $T$ and $N$ tend to approach infinity:

$Z_{N, T}^{\mathrm{HNC}}=\sqrt{\frac{N}{2 K}}\left(W_{N, T}^{\mathrm{HNC}}-K\right)_{T, N \rightarrow \infty}^{\vec{d}} N(0,1)$

where $Z_{N, T}^{H N C}$ is the $z$ statistic, $N$ is the number of crosssections and $K$ is the optimal lag length. Moreover, Dumitrescu and Hurlin (2012) also argue that if $T$ tends to infinity, the individual Wald statistics are independently identically distributed with the mean individual Wald statistic being equal to $K$ and its variance being equal to $2 \mathrm{~K}$. A standardized $Z$ statistic $\left(Z_{N, T}^{\mathrm{HNC}}\right)$ is then approximately calculated for the mean Wald statistic of the HNC null hypothesis which can be specified as:

$Z_{N, T}^{\mathrm{HNC}}=\frac{\sqrt{N}}{\sqrt{\operatorname{Var}\left(\tilde{W}_{i, T}\right)}}\left[W_{N, T}^{\mathrm{HNC}}-E \tilde{W}_{i, T}\right]$

A graphical illustration of the empirical strategy is depicted in Fig. 3.

\section{Results and discussion}

The results from the second generation panel unit root tests are reported in Table 2. It is apparent from both the CADF and the CIPS test results that all the variables are nonstationary at their respective level forms. The statistical insignificance of the corresponding test statistics fails to reject the null hypothesis of non-stationarity in this regard. However, all the variables do become stationary at their first differences, thus, indicating a common order of integration [i.e., I(1)] which can be perceived from the statistical significance of the corresponding test statistics under both the unit root estimation techniques.

The Westerlund (2007) panel cointegration test results, in the context of models (1), (2) and (3), are presented in Table 3. The statistical significances of the test statistics reject the null hypothesis of no cointegrating relationships between the variables in the respective models. Hence, in the context of model (1), it can be said that REC across all the four South Asian economies has long-run associations with real crude oil prices and other macroeconomic aggregates controlled for in the empirical modeling. The results coincide with the findings by Apergis and Payne (2015) in which the authors too found a long-run association between per capita REC and real oil prices in the context of 11 South American economies. Similarly, in the context of model (2), it can also be asserted that there are long-run associations between the shares of RE in aggregate final energy consumption figures and crude oil prices and all the other control variables for all the four South Asian economies. Finally, the statistical significance of the test statistics in the context of model (3) also provides statistical validity regarding long-run associations between the renewable electricity share in aggregate electricity outputs and the other independent variables. Thus, the confirmation of the long-run associations calls for further investigation of the long-run conditional elasticities between the concerned variables.

Table 4 displays the long-run elasticity estimates from the MG, CCEMG and the AMG regression analyses. It is apparent from the overall results that the elasticity estimates, in the context of the three models, are robust across the alternate panel data regression techniques to the 


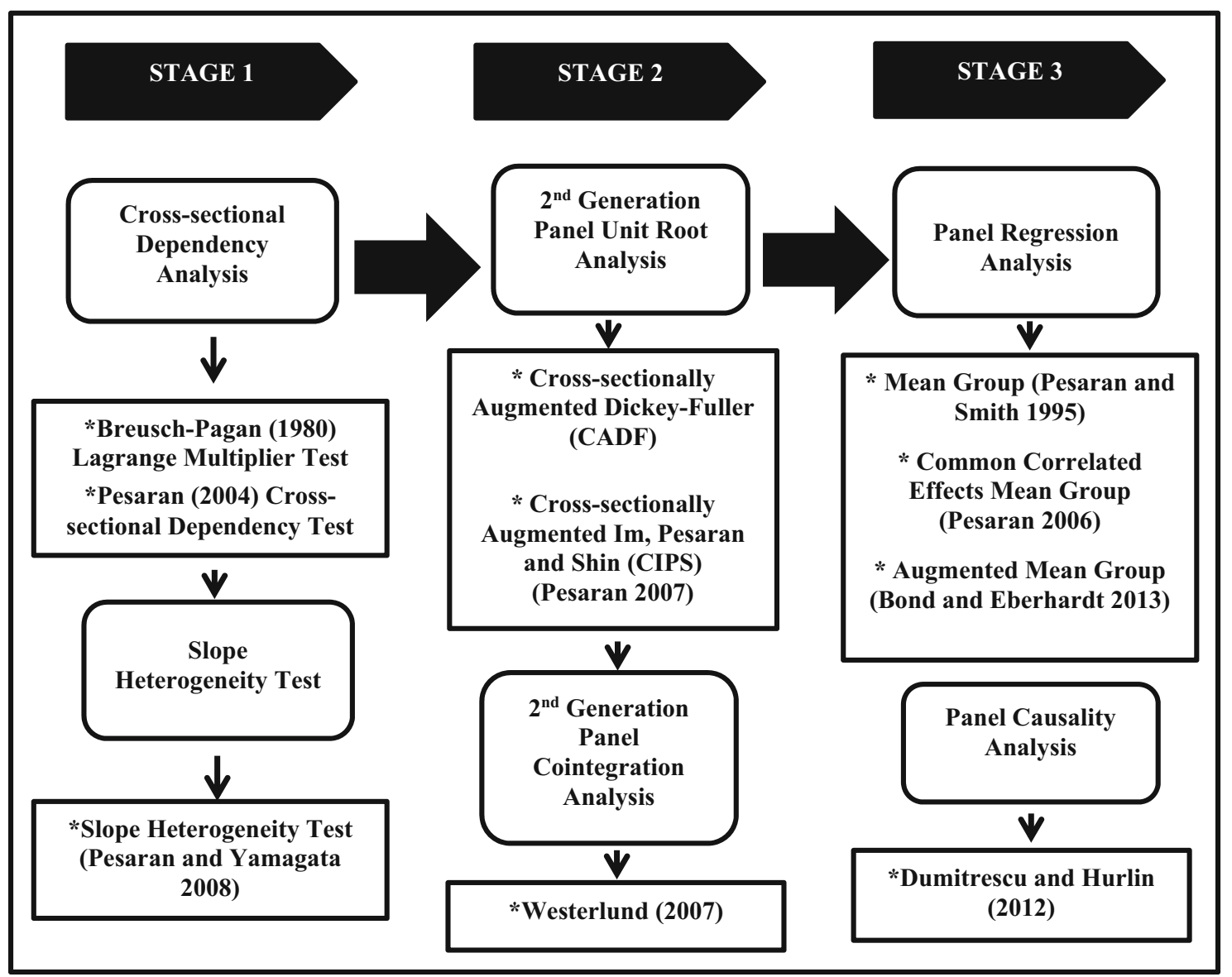

Fig. 3 Methodological schema of the paper

predicted signs and their corresponding statistical significance. In the context of model (1), the statistical significances of the elasticity parameters attached to InROILP and $\operatorname{lnROILP}{ }^{2}$ confirm the nonlinearity of the REC-crude oil price nexus in the context of the selected net oil-importing South Asian economies. Moreover, the negative signs of the elasticity parameters attached to lnROILP advocate in favor of positive shocks to real crude oil prices, initially, not being able to facilitate REC across the concerned economies. The corresponding elasticity estimates implicate that a $1 \%$ rise in real crude oil prices is accompanied by a fall in the REC levels on average by $2.35-3.59 \%$, ceteris paribus. The negative REC-crude oil price nexus was also reported in the study by Sadorsky (2009) for Canada, Japan, the UK and the USA. It is worth mentioning that Japan, the UK and the USA are all net importers of crude oils which further justify our results in the context of the four South Asian net oil importers.

However, although initially the REC-crude oil price nexus is found to be negative, the statistical significance and the positive signs of the estimated elasticity parameters attached to $\operatorname{lnROILP}{ }^{2}$ suggest that beyond a threshold level of real crude oil price the relationship reverses to induce greater consumption of RE resources within the South Asian nations. Based on the elasticity estimates, the threshold level of real crude oil price is predicted to be around 135 US dollars per barrel in constant 2016 prices. ${ }^{4}$ The corresponding elasticity estimates show that, beyond this predicted real crude oil price threshold, a further rise in the real price of crude oil by $1 \%$ is accompanied by increments in the REC levels by $0.10-0.14 \%$, on average, ceteris paribus. Therefore, it can be asserted that initially following a rise in crude oil prices the substitution of the imported crude oils via the RE alternatives, within the selected South Asian nations, may not be possible due to the predominant reliance of these nations on oil imports to source energy for generating their respective national outputs. A particular reason behind such imported oil-

\footnotetext{
${ }^{4}$ The threshold real crude oil price level is estimated at the average of the RGDP figures of the selected South Asian economies in 2018 due to the REC-ROILP nexus being conditional on the level of RGDP. Also, it is to be noted that the predicted threshold level of real crude oil price (135 US dollars per barrel in constant 2016 prices) is well above the real crude oil price level in 2018 (46 US dollars per barrel in constant 2016 prices) which further explains the reason behind the prevailing imported oil dependency amidst the selected South Asian NOIC.
} 
Table 2 Panel unit root test with cross-sectional dependency results

\begin{tabular}{|c|c|c|c|c|c|}
\hline \multirow[t]{2}{*}{ Variable } & \multicolumn{2}{|l|}{ Level } & \multicolumn{2}{|l|}{ 1st difference } & \multirow[t]{2}{*}{ Order of integration } \\
\hline & Intercept & Intercept and trend & Intercept & Intercept and trend & \\
\hline \multicolumn{6}{|l|}{ Pesaran CADF test } \\
\hline $\operatorname{lnREC}$ & -1.488 & -2.429 & $-2.519 * * *$ & $-3.220 * *$ & $\mathrm{I}(1)$ \\
\hline lnRES & -1.116 & -.1717 & -0.453 & $-3.204 * *$ & $\mathrm{I}(1)$ \\
\hline $\operatorname{lnRELEC}$ & -1.823 & -2.511 & $-3.133 * * *$ & $-3.072 * *$ & $\mathrm{I}(1)$ \\
\hline $\operatorname{lnROILP}^{2} / \operatorname{lnROILP}{ }^{2}$ & -1.610 & -1.700 & $-2.819 * * *$ & $-3.700^{* * *}$ & $\mathrm{I}(1)$ \\
\hline $\operatorname{lnRGDP}$ & -1.691 & -2.222 & -2.281 & $-3.979 * * *$ & $\mathrm{I}(1)$ \\
\hline $\operatorname{lnROILP} * \operatorname{lnRGDP}$ & -1.283 & -1.586 & $-2.456^{*}$ & $-3.998 * * *$ & $\mathrm{I}(1)$ \\
\hline lnDEPEND & -1.919 & -2.283 & $-3.892 * * *$ & $-3.794 * * *$ & $\mathrm{I}(1)$ \\
\hline $\operatorname{lnCO} 2$ & -1.849 & -2.721 & $-3.216^{* * *}$ & $-3.209 * *$ & $\mathrm{I}(1)$ \\
\hline $\ln \mathrm{TO}$ & -1.969 & -1.806 & $-2.435^{*}$ & $-3.983 * * *$ & $\mathrm{I}(1)$ \\
\hline \multicolumn{6}{|l|}{ Pesaran CIPS test } \\
\hline $\ln R E C$ & -2.001 & -2.129 & $-6.001 * * *$ & $-6.084 * * *$ & $\mathrm{I}(1)$ \\
\hline $\operatorname{lnRES}$ & -2.068 & -1.954 & $-4.945^{* * *}$ & $-5.023 * * *$ & $\mathrm{I}(1)$ \\
\hline lnRELEC & -2.101 & -2.023 & $-5.682 * * *$ & $-5.678 * * *$ & $\mathrm{I}(1)$ \\
\hline $\operatorname{lnROILP}^{2} / \operatorname{lnROILP}{ }^{2}$ & -1.610 & -1.700 & $-3.320 * * *$ & $-3.952 * * *$ & $\mathrm{I}(1)$ \\
\hline lnRGDP & -1.677 & -2.113 & $-4.417 * * *$ & $-4.389 * * *$ & $\mathrm{I}(1)$ \\
\hline $\operatorname{lnROILP} * \operatorname{lnRGDP}$ & -0.552 & -1.895 & $-3.709 * * *$ & $-3.764 * * *$ & $\mathrm{I}(1)$ \\
\hline lnDEPEND & -1.995 & -1.942 & $-5.183 * * *$ & $-5.165^{* * *}$ & $\mathrm{I}(1)$ \\
\hline $\operatorname{lnCO} 2$ & -2.139 & -2.019 & $-5.445^{* * *}$ & $-5.541 * * *$ & $\mathrm{I}(1)$ \\
\hline $\ln \mathrm{TO}$ & -1.615 & -1.849 & $-5.295 * * *$ & $-5.288 * * *$ & $\mathrm{I}(1)$ \\
\hline
\end{tabular}

The optimal lags are chosen based on the akaike information criterion (AIC)

$* * *, * *, *$ Statistical significance at $1 \%, 5 \%$ and $10 \%$ levels, respectively

Table 3 Westerlund cointegration test results

\begin{tabular}{|c|c|c|c|c|c|c|}
\hline \multirow[t]{2}{*}{ Test statistic } & \multicolumn{2}{|l|}{ Model (1) } & \multicolumn{2}{|l|}{ Model (2) } & \multicolumn{2}{|l|}{ Model (3) } \\
\hline & Value & $p$ value & Value & $p$ value & Value & $p$ value \\
\hline $\mathrm{Gt}$ & $-3.101 * * *$ & 0.000 & $-3.286 * * *$ & 0.000 & $-2.714 *$ & 0.100 \\
\hline $\mathrm{Ga}$ & $-4.645^{* * *}$ & 0.000 & $-4.883^{* * *}$ & 0.000 & $-5.019 * * *$ & 0.000 \\
\hline $\mathrm{Pt}$ & -6.145 & 0.200 & $-7.836 * * *$ & 0.000 & $-5.664 *$ & 0.100 \\
\hline $\mathrm{Pa}$ & $-5.111^{*}$ & 0.100 & $-4.660 *$ & 0.100 & -2.975 & 0.300 \\
\hline
\end{tabular}

The bootstrapping regression is conducted with 100 replications. The optimal lag selection is based on AIC $* * *, *$ Statistical significance at $1 \%$ and $10 \%$ levels, respectively dependence can largely be attributed to the unavailability of indigenous natural oil endowments across South Asia. This, coupled with the limited opportunities to locally generate power from renewables in most of the selected South Asian countries, tends to restrain the RET process in the short-run. However, a persistent small rise in crude oil prices, approaching toward the predicted threshold, along with economic development over time would induce the RET phenomenon in these economies which possibly could be due to the gradual phasing out of the imported-oil dependencies of these economies over time. This mechanism can be explained using the estimated economic growth elasticities of REC. The positive signs of the statistically significant elasticity parameters attached to lnRGDP suggest economic growth does exhibit favorable impacts to facilitate RET within the economies which could be playing a key role in reducing their imported-oil dependencies. Moreover, the positive signs of the statistically significant elasticity parameters attached to the interaction term further advocate in favor of the joint favorable impacts of economic growth and rising crude oil prices concerning the facilitation REC within the four 


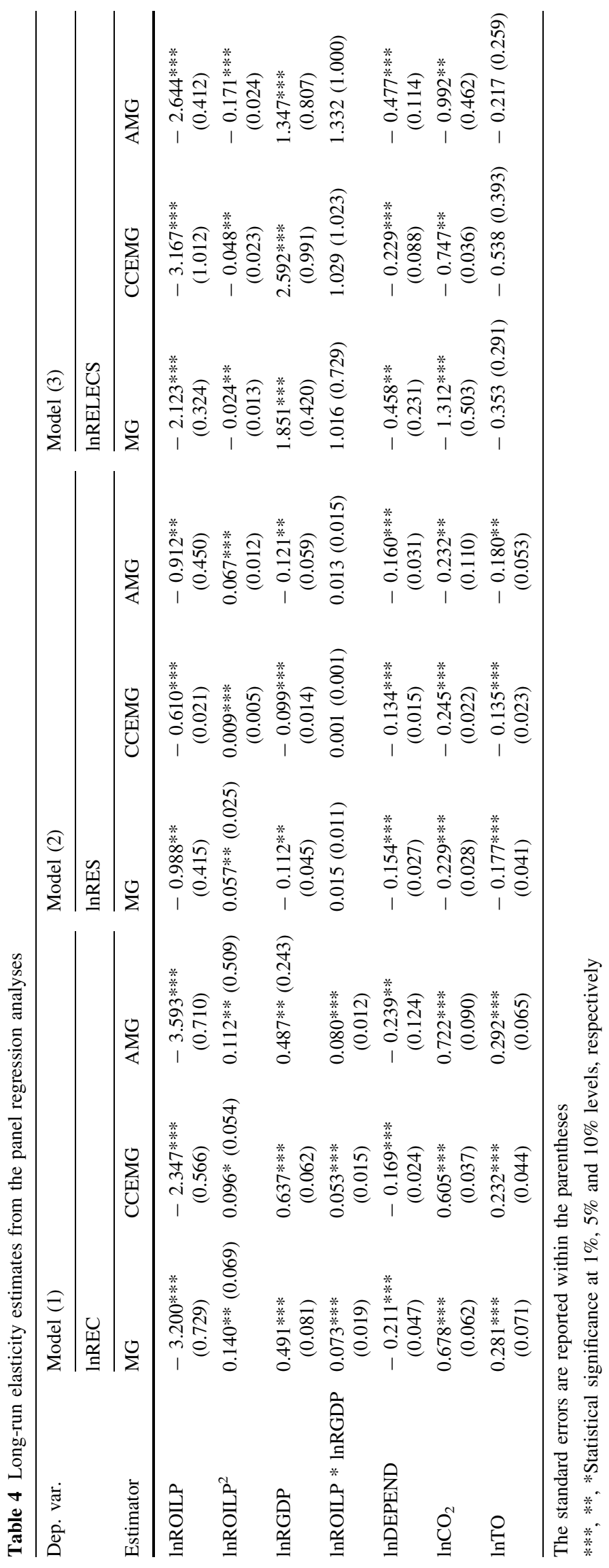


South Asian nations. ${ }^{5}$ Furthermore, dependency on imported oils is also found to dampen the prospects of RET across South Asia. The negative signs of the statistically significant elasticity parameters attached to lnDEPEND denote that a $1 \%$ rise in the volume of energy imports leads to a fall in the REC levels on average by $0.17-0.24 \%$, ceteris paribus. Thus, reducing oil imports, which can be said to be synonymous with a reduction in imported-energy dependencies, is key to boosting REC within the South Asian countries. This finding is similar to the conclusion made by Damette and Marques (2019) for 24 European Union economies.

The other important findings include the positive association between $\mathrm{CO}_{2}$ emissions and REC which explicitly points out toward the REC being triggered by environmental adversities stemming from air pollutions which, in turn, can largely be attributed to the combustion of the imported oils. Thus, rising $\mathrm{CO}_{2}$ can be claimed to instigate the substitution between imported oils and the RE alternatives. The positive $\mathrm{CO}_{2}$-REC nexus is parallel to the findings by Sadorsky (2009) in the context of the G7 countries. On the other hand, the regression results also imply that liberalizing trade barriers generate favorable outcomes concerning the facilitation of the RET phenomenon within the selected economies. This is evident from the positive signs of the statistically significant elasticity parameters attached to InOPEN which imply that a $1 \%$ rise in the trade openness indices enhances REC by $0.23-0.29 \%$ on average, ceteris paribus. A specific reason behind this finding could be interpreted as lower trade barriers facilitating the cross-border flows of renewable power within the concerned economies whereby the levels of REC can justifiably be expected to go up. Similar findings were reported in the study by Murshed (2018) which included Nepal as an additional South Asian economy along with the four nations considered in this paper.

As far as the shares of renewables in total final energy consumption figures are concerned, the elasticity estimates in the context of model (2), as reported in Table 4, also confirm the nonlinear association between renewable energy shares and real crude oil prices. The negative and the positive signs of the statistically significant estimated elasticity parameters attached to lnROILP and lnROILP ${ }^{2}$, respectively, provide support to this claim. The results show that a $1 \%$ rise in real crude oil prices initially curbs the shares of renewables by $0.61-0.99 \%$ on average, ceteris paribus. The small magnitudes of the predicted elasticities imply that the share of renewables in aggregate final energy consumption figures is pretty inelastic to changes in crude

\footnotetext{
${ }^{5}$ Due to the statistical significance of the interaction term, the level of RGDP needs to be considered in estimating the real crude oil price threshold.
}

oil prices. However, beyond a certain threshold level of real crude oil price, a further increase in the crude oil prices by $1 \%$ enhances renewable energy shares on average by $0.01-0.07 \%$, ceteris paribus. Hence, once again it can be concluded that the rising price of crude oil in the international markets does not instantaneously lead to the substitution of crude oil via the RE alternatives. However, beyond a certain price level, the substitution does take place to some extent whereby the RET phenomenon can be expected to take off.

Among the other key findings in the context of model (2), economic growth, although attributing to higher REC levels, does not simultaneously guarantee a rise in the share of $\mathrm{RE}$ in the total final energy consumption figures. A $1 \%$ rise in the real value of GDP is found to reduce the RE shares by $0.10 \% 0.12 \%$, on average, ceteris paribus. Hence, it can be said that the national outputs of these nations are relatively more intensive in the use of the NRE resources which further implicates that the imported oildependency of the concerned South Asian nations. Moreover, quite expectedly, the marginal impacts of importedoil dependency are also found to dampen the RE shares as perceived from the negative and statistically significant estimates of the elasticity parameters attached to $\operatorname{lnDE}$ PEND in the context of model (2). On the other hand, rising carbon-dioxide emissions, despite accounting for higher REC levels, actually lead to lower shares of renewables in aggregate final energy consumption figures across the concerned South Asian countries. This implies that although environmental pollution does trigger REC to some extent it does not undermine the use of the NRE resources, thus, inhibiting the overall RET phenomenon. Finally, openness to trade is also found to exert adverse impacts on RE shares which corroborates to the findings by Murshed (2018). A 1\% rise in the trade openness indices of the selected South Asian economies is found to reduce the RE shares by $0.14-0.18 \%$, on average, ceteris paribus. The negative trade openness-renewable energy share nexus in the context of middle-income economies was also highlighted in the study by Murshed (2020).

Finally, the regression results in the context of model (3), as reported in Table 4, also confirm the nonlinear association between movements in real prices of crude oil and the shares of renewable electricity in aggregate electricity output levels within the selected South Asian economies. The statistical significances of the estimated elasticities of REC concerning changes in real crude oil price and its squared term affirm the quadratic association between these two variables. However, the negative signs of the elasticity parameters attached to both InROILP and InROILP ${ }^{2}$ explicitly point out the fact that rising crude oil prices do not stimulate the transition from non-renewable 
to renewable primary energy use for electricity generation purposes in the selected NOIC across South Asia. This is a pretty concerning finding in the context of energy security within these nations. However, it is to be noted that the magnitudes of the estimated elasticities of the parameters attached to $\operatorname{lnROILP}{ }^{2}$ are relatively lower, and less than one, in comparison to the predicted elasticities of the parameters attached to lnROILP. This implies that as the real price of crude oil increases to a large extent, its dampening impact on renewable electricity shares seems to gradually diminish. Hence, it can be expected that at extremely high crude oil prices, the marginal negative impact on the renewable electricity share can be anticipated to be completely phased out which, in turn, could go on to raise the share in the future.

The other key results in the context of model (3) reveal that higher economic growth elevates the share of renewable electricity within the selected South Asian economies. A $1 \%$ rise in the real GDP figures is found to increase the shares by $1.35-2.59 \%$, on average, ceteris paribus. This implies that the growth of the economy empowers the concerned economies to get over the dependency on imported oils for generating electricity, thus, lessening the shares of non-renewable electricity. Moreover, imported oil-dependency is found to undermine the renewable electricity share within the four NOIC within South Asia. Furthermore, rising carbon-dioxide emissions are found to ineffective in enhancing the share of renewables in aggregate electricity outputs which tends to suggest that there has somewhat been an acceptance regarding the trade-off between economic growth and environmental pollution. As a result, rising carbon-dioxide emissions across these South Asian economies inhibit the overall prospects of transition from non-renewable to renewable electricity generation.

The regression analyses are followed by the DH causality examinations. The results from the causality tests are reported in Table 5. It is evident from the statistical significance of the $z$-bar statistics that there is a bidirectional causal association between real crude oil price and REC. This finding is parallel to the findings by Apergis and Payne (2014a) in the context of the Central American economies. Moreover, findings from the causality analyses also reveal unidirectional causations stemming from real crude oil prices to the shares of RE and renewable electricity in total final energy consumption and aggregate electricity output levels, respectively. Hence, keeping the long-run elasticity estimates into consideration, the overall findings from the causality analysis advocate in favor of movements in real prices of crude oil, in the international market, influencing the overall prospects of RET within the selected NOIC across South Asia. Thus, safeguarding the concerned economies to overcome the predominant dependence on their oil imports is key to undergoing the non-renewable to RET within these economies.

\section{Conclusions and policy implications}

Rising apprehensions in the context of energy insecurity and environmental degradation, on a global scale, in the future has sparked the need to undergo RET worldwide. The importance of transitioning from consumption of nonrenewable to RE resources is of greater relevance in the context of the NOIC since predominant dependency on imported oils often goes on to bottleneck their prospects of

Table 5 The Dumitrescu-Hurlin panel causality test results

\begin{tabular}{|c|c|c|c|c|c|}
\hline \multicolumn{2}{|l|}{ Model (1) } & \multicolumn{2}{|l|}{ Model (2) } & \multicolumn{2}{|l|}{ Model (3) } \\
\hline Null hypothesis $\left(H_{\mathrm{o}}\right)$ & $Z$-bar stat. & Null hypothesis $\left(H_{\mathrm{o}}\right)$ & $Z$-bar stat. & Null hypothesis $\left(H_{\mathrm{o}}\right)$ & Z-bar stat. \\
\hline $\operatorname{lnROILP} \rightarrow \operatorname{lnREC}$ & $8.382 * * *(0.000)$ & $\operatorname{lnROILP} \rightarrow \operatorname{lnRES}$ & $4.649 * * *(0.000)$ & $\operatorname{lnROILP} \rightarrow \operatorname{lnRELEC}$ & $6.071 * * *(0.003)$ \\
\hline $\operatorname{lnREC} \rightarrow \operatorname{lnROILP}$ & $2.296 * *(0.030)$ & $\operatorname{lnRES} \rightarrow \operatorname{lnROILP}$ & $1.192(0.231)$ & $\operatorname{lnRELEC} \rightarrow \operatorname{lnROILP}$ & $1.874(0.382)$ \\
\hline $\operatorname{lnRGDP} \rightarrow \operatorname{lnREC}$ & $9.841 * * *(0.000)$ & $\operatorname{lnRGDP} \rightarrow \operatorname{lnRES}$ & $3.351 * * *(0.002)$ & $\operatorname{lnRGDP} \rightarrow \operatorname{lnRELEC}$ & $3.298 * * *(0.001)$ \\
\hline $\operatorname{lnREC} \rightarrow \operatorname{lnRGDP}$ & $2.113 * *(0.035)$ & $\operatorname{lnRES} \rightarrow \operatorname{lnRGDP}$ & $1.034(0.300)$ & $\operatorname{lnRELEC~} \rightarrow \operatorname{lnRGDP}$ & $5.570 * * *(0.000)$ \\
\hline $\operatorname{lnDEPEND} \rightarrow \operatorname{lnREC}$ & $1.147(0.684)$ & lnDEPEND $\rightarrow$ lnRES & $6.112 * * *(0.000)$ & $\operatorname{lnDEPEND} \rightarrow \operatorname{lnRELEC}$ & $3.396 * * *(0.001)$ \\
\hline $\operatorname{lnREC} \rightarrow \operatorname{lnDEPEND}$ & $3.083^{* * *}(0.002)$ & lnRES $\rightarrow$ lnDEPEND & $8.222 * * *(0.000)$ & $\operatorname{lnRELEC} \rightarrow \operatorname{lnDEPEND}$ & $0.684(0.297)$ \\
\hline $\operatorname{lnCO}_{2} \rightarrow \operatorname{lnREC}$ & $1.271(0.682)$ & $\operatorname{lnCO}_{2} \rightarrow \operatorname{lnRES}$ & $6.671 * * *(0.000)$ & $\operatorname{lnCO}_{2} \rightarrow \operatorname{lnRELEC}$ & $7.487 * * *(0.000)$ \\
\hline $\operatorname{lnREC} \rightarrow \operatorname{lnCO}_{2}$ & $2.708 * * *(0.007)$ & $\operatorname{lnRES} \rightarrow \operatorname{lnCO}_{2}$ & $4.019 * * *(0.000)$ & $\operatorname{lnRELEC~} \rightarrow \operatorname{lnCO}_{2}$ & $0.912(0.306)$ \\
\hline $\operatorname{lnTO} \rightarrow \operatorname{lnREC}$ & $11.286 * * *(0.000)$ & $\operatorname{lnTO} \rightarrow \operatorname{lnRES}$ & $6.993 * * *(0.000)$ & $\operatorname{lnTO} \rightarrow \operatorname{lnRELEC}$ & $2.335 * *(0.020)$ \\
\hline $\operatorname{lnREC} \rightarrow \operatorname{lnTO}$ & $2.228 * * *(0.006)$ & $\operatorname{lnRES} \rightarrow \operatorname{lnTO}$ & $0.442(0.341)$ & $\operatorname{lnRELEC~} \rightarrow \operatorname{lnTO}$ & $2.347 * *(0.018)$ \\
\hline
\end{tabular}

$\rightarrow$ Indicates does not Granger cause; The $p$ values, computed using 100 bootstrap replications, are reported within the parentheses

$* * *, * *, *$ Statistical significance at $1 \%, 5 \%$ and $10 \%$ levels, respectively 
RET. Against this milieu, this paper attempted to investigate the impacts of exogenous shocks to the real crude oil prices on the RET phenomenon within four net oil-importing South Asian economies namely Bangladesh, India, Pakistan and Sri Lanka. The overall results from the econometric analyses provided statistical validity regarding the nonlinear U-shaped association between crude oil price and REC. Based on the estimates, the threshold level of real crude oil price was estimated to be around 135 US dollars per barrel which is way above the real crude oil price level of 45 US dollars per barrel in 2018. Therefore, the estimated threshold implies that the real price of crude oils has to increase by almost three-fold in order to induce higher REC levels within these economies. This is a crucial finding since it partially explains the possible reason behind the existing imported-oil dependency amidst the selected South Asian NOIC. Moreover, following the ongoing Novel Corona Virus (COVID-19) pandemic, the price of crude oil is on the verge of going negative due to a stern fall in the global crude oil demand (Widdershoven 2020, May 03). Under such circumstances, the degree of oil-dependency amidst the selected South Asian NOIC can be anticipated to surge which, in turn, could adversely impact the environmental quality within these economies further. Although the results from the empirical analysis implicated that the current real price of oil is way below the predicted threshold level, and the difference can be expected to widen particularly due to the COVID-19 pandemic. Hence, it is pertinent for the concerned economies to drift away from their predominant dependence on the imported oils for power generation purposes and undergo RET for the sake of establishing environmental well-being at the earliest.

Among the other key findings, statistical evidence regarding a similar nonlinear association between crude oil prices and RE share in total final energy consumption figures was also ascertained. Furthermore, the results also suggested that the relationship between crude oil prices and the share of renewable electricity in aggregate electricity outputs is also nonlinear; however, higher crude oil prices were not found to enhance the renewable electricity share in the context of the concerned South Asian economies. Finally, the causality findings revealed that changes in the crude oil prices influence movements in REC and the shares of RE and renewable electricity in total final energy consumption and aggregate electricity outputs, respectively.

Therefore, in line with these aforementioned findings, it is ideal for the associated governments to adopt appropriate strategies to gradually phase-out the conventional imported-oil dependency of these South Asian economies which, in turn, is likely to facilitate the overall RET phenomenon to a large extent. More importantly, keeping the immense potentials of cross-border RE trade within South Asia into cognizance, it is recommended to liberalize the corresponding trade barriers to facilitate the flows of renewable power into the four net oil-importing South Asian economies considered in this paper. For instance, these economies can look forward to importing hydroelectric power from Nepal while importing geothermal energy from Bhutan. Although the prospects of power-trade across South Asia are often marginalized due to acute geopolitical and other macroeconomic issues, it is pertinent to overcome these hindrances keeping the attainment of the SDG into cognizance, particularly via the implementation of public policies that are precisely designed to foster RET within the South Asian region.

As part of the future scope of research, this paper can be replicated individually for the all the four net oil-importing South Asian economies to identify the possible heterogeneous impacts of crude oil prices on the REC levels. Moreover, this investigation can also be performed in the context of the net oil-exporting nations to understand the contrasting dynamics of the REC-crude oil price nexus ignoring the imported-oil dependency issues.

Funding No funding was received to conduct this research.

Compliance with ethical standards

Conflict of interest The authors declare that they have no conflict of interest.

\section{Appendix}

See Figs. 4 and 5 and Tables 6 and 7. 

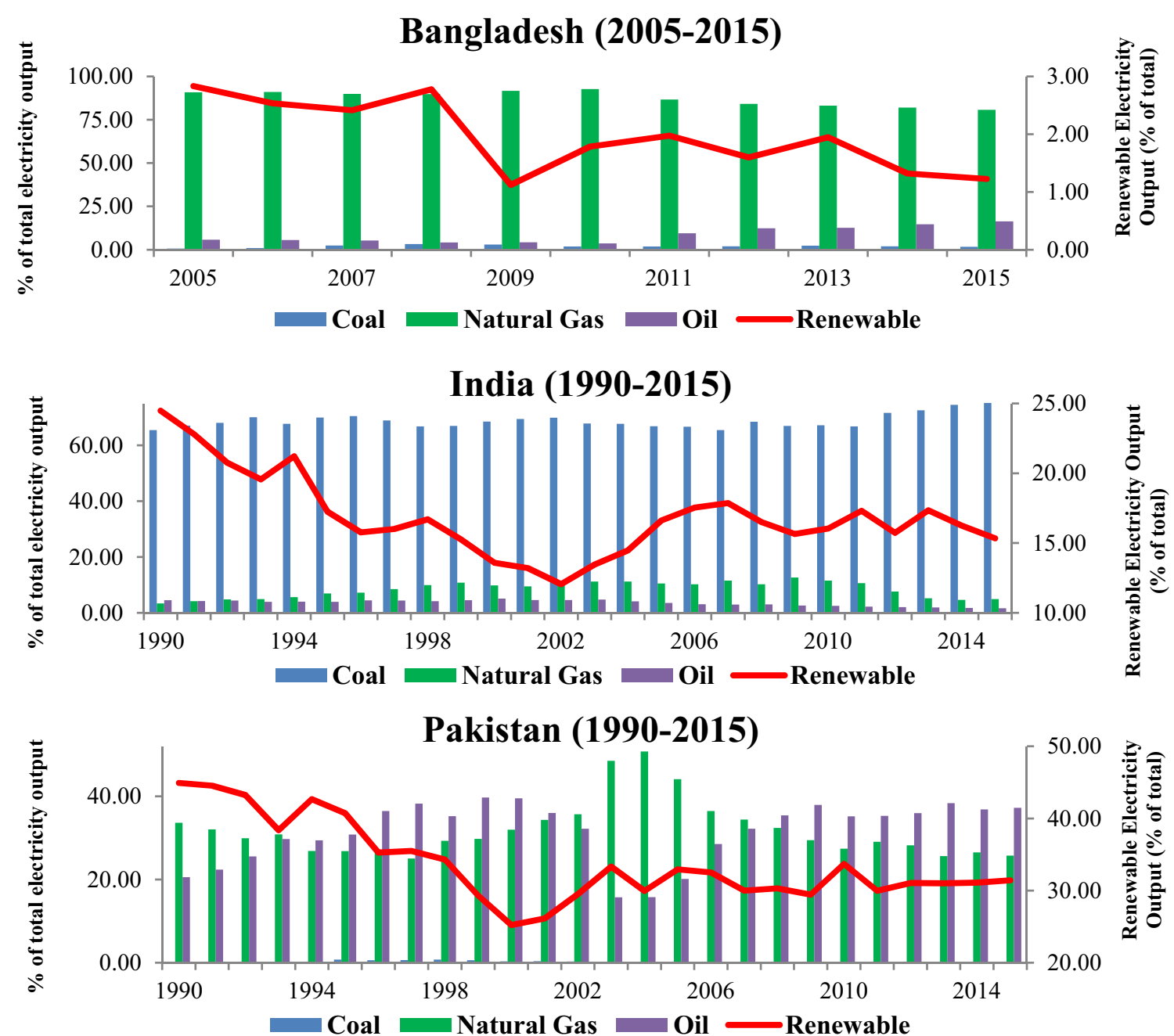

Sri Lanka (1990-2015)

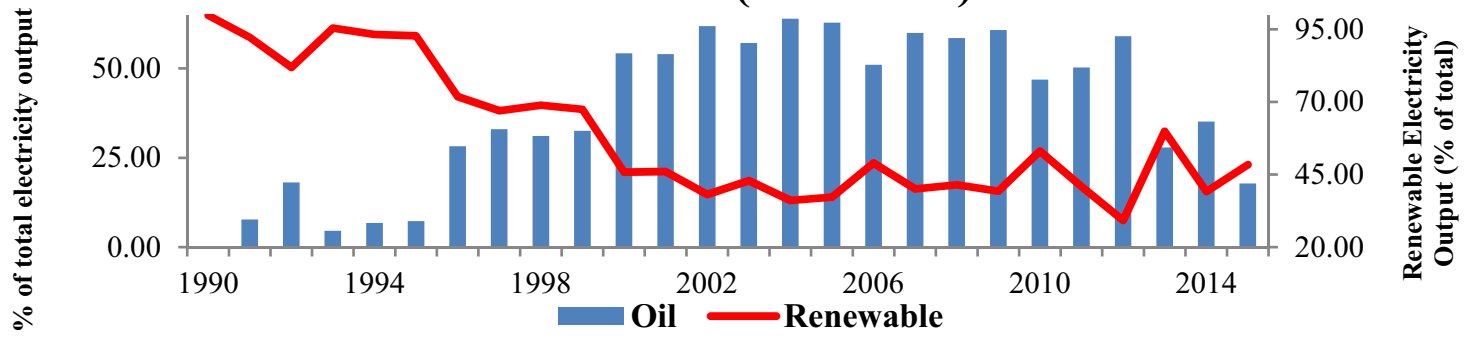

Fig. 4 Energy-mixes for electricity generation purposes across the selected South Asian nations. Source: World Development Indicators (World Bank 2019) 
Renewable Energy Consumption Shares (1990-2015)

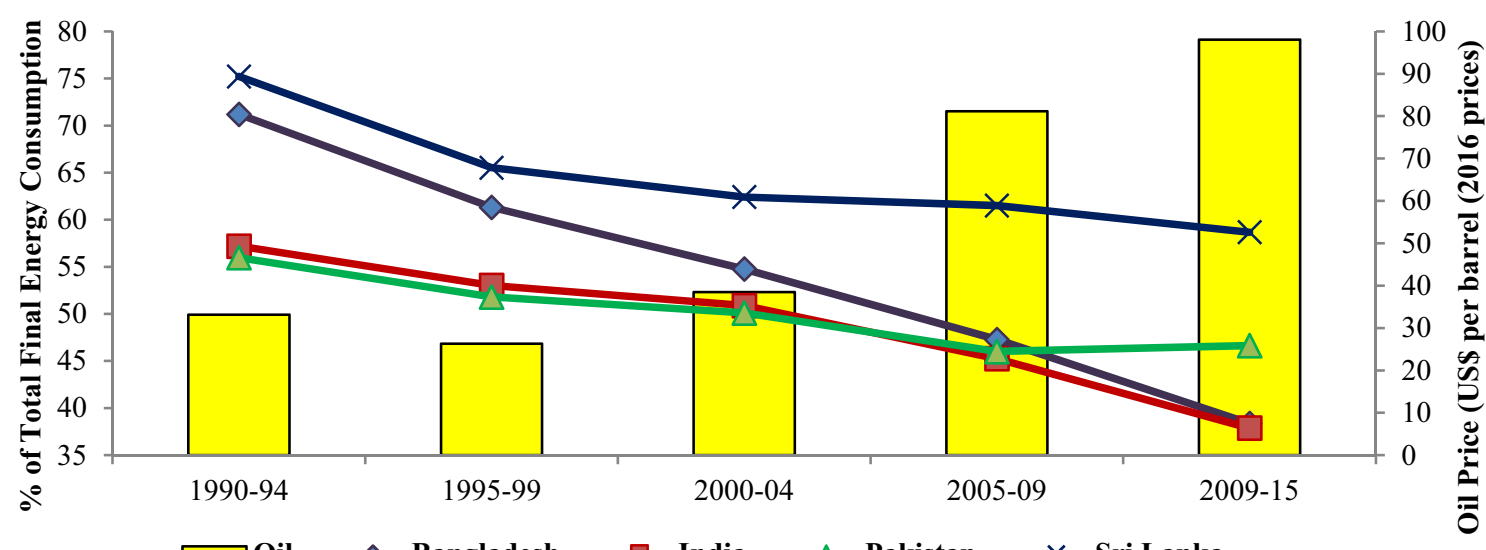

Renewable Electricity Output Shares (1990-2015)

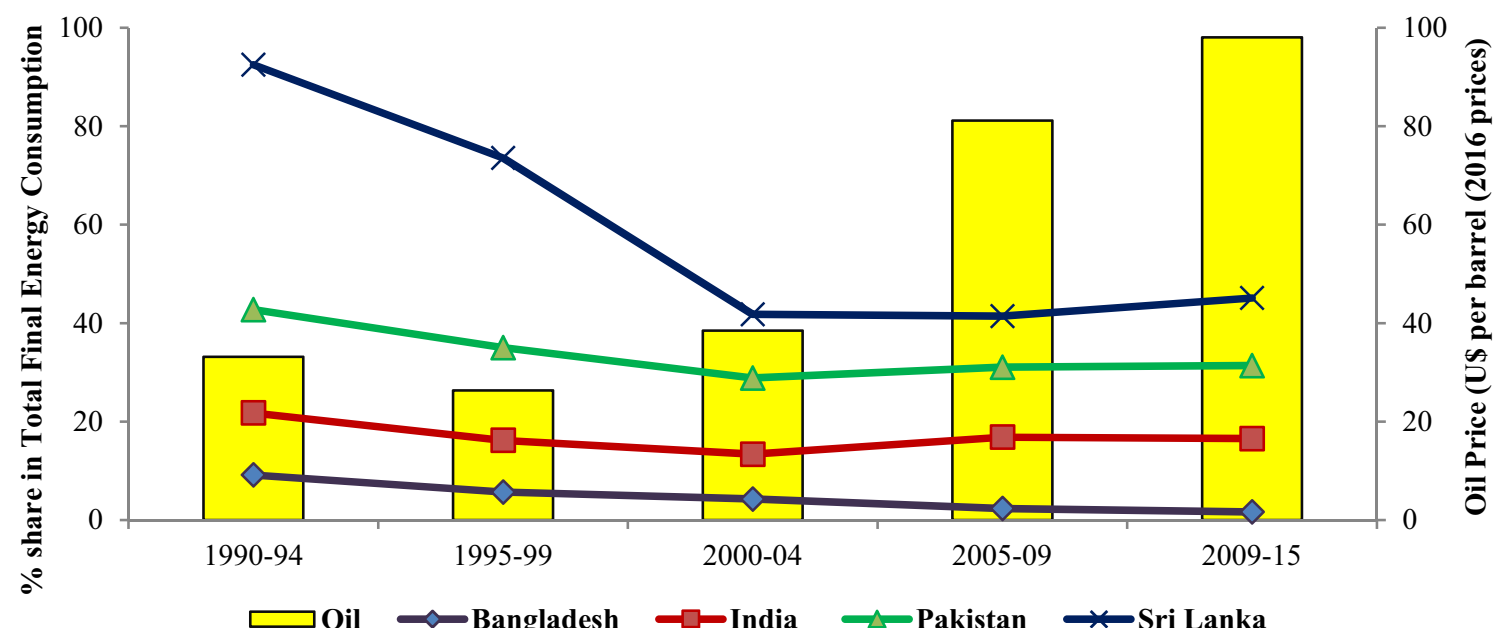

Fig. 5 Trends in renewable energy consumption and renewable electricity output shares and real oil prices. Source: World Bank (2019)

Table 6 Descriptive statistics

\begin{tabular}{lllllllll}
\hline Variable & lnREC & lnRES & lnRELEC & lnROILP & LnRGDP & LnDEPEND & LnCO $_{2}$ & LnTO \\
\hline Mean & 24.002 & 3.954 & 2.873 & 3.883 & 25.762 & 2.847 & -0.549 & 3.656 \\
SD & 1.455 & 0.195 & 1.132 & 0.528 & 1.314 & 0.582 & 0.601 & 0.408 \\
Minimum & 22.136 & 3.548 & 0.115 & 2.930 & 23.749 & 1.583 & -1.672 & 2.741 \\
Maximum & 26.437 & 4.358 & 4.604 & 4.777 & 28.675 & 3.761 & 0.256 & 4.485 \\
Skewness & 0.492 & -0.156 & -0.877 & 0.289 & 0.678 & -0.256 & -0.320 & 0.155 \\
Kurtosis & 1.841 & 2.409 & 2.922 & 1.910 & 2.414 & 1.782 & 2.627 & 2.410 \\
Observations & 116 & 116 & 116 & 116 & 116 & 116 & 116 & 116 \\
\hline
\end{tabular}


Table 7 Cross-sectional dependency and slope heterogeneity test results

\begin{tabular}{|c|c|c|c|c|c|c|}
\hline & \multicolumn{2}{|l|}{ Model (1) } & \multicolumn{2}{|l|}{ Model (2) } & \multicolumn{2}{|l|}{ Model (3) } \\
\hline & Statistic & $P$ value & Statistic & $P$ value & Statistic & $P$ value \\
\hline \multicolumn{7}{|l|}{ CD tests } \\
\hline Breusch-Pagan LM & $133.345^{* * *}$ & 0.000 & $107.05 * * *$ & 0.000 & $121.02 * * *$ & 0.000 \\
\hline Pesaran CD & $3.112 * * *$ & 0.002 & $1.851 * *$ & 0.045 & $1.911 * *$ & 0.039 \\
\hline \multicolumn{7}{|l|}{ Slope heterogeneity test } \\
\hline$\tilde{\Delta}$ & $15.041 * * *$ & 0.000 & $14.021 * * *$ & 0.000 & $15.449 * * *$ & 0.000 \\
\hline$\tilde{\Delta}_{\text {adj }}$ & $15.019 * * *$ & 0.000 & $14.392 * * *$ & 0.000 & $16.012 * * *$ & 0.000 \\
\hline
\end{tabular}

***, **Statistical significance at $1 \%$ and $5 \%$ levels, respectively

\section{References}

Apergis N, Payne JE (2014a) Renewable energy, output, $\mathrm{CO}_{2}$ emissions, and fossil fuel prices in Central America: evidence from a nonlinear panel smooth transition vector error correction model. Energy Econ 42:226-232

Apergis N, Payne JE (2014b) The causal dynamics between renewable energy, real GDP, emissions and oil prices: evidence from OECD countries. Appl Econ 46(36):4519-4525

Apergis N, Payne JE (2015) Renewable energy, output, carbon dioxide emissions, and oil prices: evidence from South America. Energy Sources B Econ Plan Policy 10(3):281-287

Ashenfelter O, Heckman J (1974) The estimation of income and substitution effects in a model of family labor supply. Econom $\mathrm{J}$ Econom Soc 42:73-85

Azad AK, Rasul MG, Khan MMK, Omri A, Bhuiya MMK, Ali MH (2014) Modelling of renewable energy economy in Australia. Energy Procedia 61:1902-1906

Bond S, Eberhardt M (2013) Accounting for unobserved heterogeneity in panel time series models. University of Oxford, Oxford

BPDB (2017) Bangladesh Power Development Board website. https:// dpdc.org.bd/article/view/52/Tariff\&

Breusch TS, Pagan AR (1980) The Lagrange multiplier test and its applications to model specification in econometrics. Rev Econ Stud 47(1):239-253

British Petroleum (2019) Statistical review of world energy 2019. British Petroleum, London

Chudik A, Pesaran MH (2013) Large panel data models with crosssectional dependence: a survey. CAFE Research Paper (13.15)

Climatoscope (2019) Emerging markets outlook 2019: energy transition in the world's fastest growing economies. Bloomberg New Energy Finance. http://global-climatescope.org/assets/data/ reports/climatescope-2019-report-en.pdf

Cunado J, Jo S, de Gracia FP (2015) Macroeconomic impacts of oil price shocks in Asian economies. Energy Policy 86:867-879

Damette O, Marques AC (2019) Renewable energy drivers: a panel cointegration approach. Appl Econ 51(26):2793-2806

Dong K, Sun R, Dong X (2018) $\mathrm{CO}_{2}$ emissions, natural gas and renewables, economic growth: assessing the evidence from China. Sci Total Environ 640:293-302

Dumitrescu EI, Hurlin C (2012) Testing for Granger non-causality in heterogeneous panels. Econ Model 29(4):1450-1460

Granger CWJ (1969) Investigating causal relations by econometric models and cross-spectral methods. Econometrica 37:424-438

Gupta E (2008) Oil vulnerability index of oil-importing countries. Energy Policy 36(3):1195-1211

Harder A (2019) Solar power costs plummet across South Asia and the Pacific. Axios. Retrieved from https://www.axios.com/solarpower-south-asia-pacific-renewable-energy-eee36b8e-bf78-483e83ed-c2544bb9b8f0.html
IRENA (2019) Renewable Power Generation Costs in 2018, International Renewable Energy Agency, Abu Dhabi. https://www. irena.org/-/media/Files/IRENA/Agency/Publication/2019/May/ IRENA_Renewable-Power-Generations-Costs-in-2018.pdf

Ji Q, Zhang D (2019) How much does financial development contribute to renewable energy growth and upgrading of energy structure in China? Energy Policy 128:114-124

Kruger P (2006) Alternative energy resources: the quest for sustainable energy. Wiley, Hoboken

Llera E, Scarpellini S, Aranda A, Zabalza I (2013) Forecasting job creation from renewable energy deployment through a valuechain approach. Renew Sustain Energy Rev 21:262-271

Marques AC, Fuinhas JA (2011) Drivers promoting renewable energy: a dynamic panel approach. Renew Sustain Energy Rev 15(3): 1601-1608

Mohsin M, Zhou P, Iqbal N, Shah SAA (2018) Assessing oil supply security of South Asia. Energy 155:438-447

Mrabet Z, Alsamara M, Saleh AS, Anwar S (2019) Urbanization and non-renewable energy demand: a comparison of developed and emerging countries. Energy 170:832-839

Murshed M (2018) Does improvement in trade openness facilitate renewable energy transition? Evidence from selected South Asian economies. South Asia Econ J 19(2):151-170

Murshed M (2019) Electricity conservation opportunities within private university campuses in Bangladesh. Energy Environ $31: 256-274$

Murshed M (2020) Are Trade Liberalization policies aligned with renewable energy transition in low and middle income countries? An instrumental variable approach. Renew Energy 151:1111-1123. https://doi.org/10.1016/j.renene.2019.11.106

Nissanka R, Konaris T (2010) Bioenergy in Sri Lanka: resources, applications and initiatives. Policy Innovation Systems for Clean Energy Security Working Paper. https://assets.publishing.ser vice.gov.uk/media/57a08b12ed915d622c000aab/PISCES_Sri_ Lanka_Bioenergy_Working_Paper.pdf

OEA (2020) Indian Wholesale Price Index (WPI) Data. Office of the Economic Advisor, India. Retrieved from: https://eaindustry.nic. in/download_data_1112.asp. Accessed 18 March 2020

Omri A, Nguyen DK (2014) On the determinants of renewable energy consumption: international evidence. Energy 72:554-560

Oseni MO (2012) Improving households' access to electricity and energy consumption pattern in Nigeria: renewable energy alternative. Renew Sustain Energy Rev 16(6):3967-3974

Painuly JP (2001) Barriers to renewable energy penetration: a framework for analysis. Renew Energy 24(1):73-89

Payne JE (2012) The causal dynamics between US renewable energy consumption, output, emissions, and oil prices. Energy Sources B Econ Plan Policy 7(4):323-330 
Pedroni P (1999) Critical values for cointegration tests in heterogeneous panels with multiple regressors. Oxford Bull Econ Stat 61(S1):653-670

Perry S, Klemeš J, Bulatov I (2008) Integrating waste and renewable energy to reduce the carbon footprint of locally integrated energy sectors. Energy 33(10):1489-1497

Pesaran MH (2004) General diagnostic tests for cross section dependence in panels. Cambridge Working Paper in Economics No. 0435

Pesaran MH (2006) Estimation and inference in large heterogeneous panels with a multifactor error structure. Econometrica 74(4):967-1012

Pesaran MH (2007) A simple panel unit root test in the presence of cross-section dependence. J Appl Econ 22(2):265-312

Pesaran MH, Smith R (1995) Estimating long-run relationships from dynamic heterogeneous panels. J Econom 68(1):79-113

Pesaran MH, Yamagata T (2008) Testing slope homogeneity in large panels. J Econom 142(1):50-93

Rentschler JE (2013) Oil price volatility, economic growth and the hedging role of renewable energy. The World Bank

Rhodes CJ (2016) The 2015 Paris climate change conference: COP21. Sci Prog 99(1):97-104

Robbins A (2016) How to understand the results of the climate change summit: Conference of Parties21 (COP21) Paris 2015

Sadorsky P (2009) Renewable energy consumption, $\mathrm{CO}_{2}$ emissions and oil prices in the G7 countries. Energy Econ 31(3):456-462

Sari R, Ewing BT, Soytas U (2008) The relationship between disaggregate energy consumption and industrial production in the United States: an ARDL approach. Energy Econ 30(5):2302-2313

Sen R, Bhattacharyya SC (2014) Off-grid electricity generation with renewable energy technologies in India: an application of HOMER. Renew Energy 62:388-398

Shah IH, Hiles C, Morley B (2018) How do oil prices, macroeconomic factors and policies affect the market for renewable energy? Appl Energy 215:87-97
Shakeel SR, Takala J, Shakeel W (2016) Renewable energy sources in power generation in Pakistan. Renew Sustain Energy Rev 64:421-434

Shen YC, Lin GT, Li KP, Yuan BJ (2010) An assessment of exploiting renewable energy sources with concerns of policy and technology. Energy Policy 38(8):4604-4616

The Economist (2014) Why is renewable energy so expensive? The Economist. Retrieved from https://www.economist.com/theeconomist-explains/2014/01/05/why-is-renewable-energy-soexpensive

Times of Islamabad (2019 December 26) Electricity prices increased yet again significantly in Pakistan. Times of Islamabad. https:// timesofislamabad.com/26-Dec-2019/electricity-prices-increasedyet-again-significantly-in-pakistan

Urmee T, Harries D, Schlapfer A (2009) Issues related to rural electrification using renewable energy in developing countries of Asia and Pacific. Renew Energy 34(2):354-357

Valentine SV (2011) Emerging symbiosis: renewable energy and energy security. Renew Sustain Energy Rev 15(9):4572-4578

Villavicencio Calzadilla P, Mauger R (2018) The UN's new sustainable development agenda and renewable energy: the challenge to reach SDG7 while achieving energy justice. J Energy Nat Resour Law 36(2):233-254

Widdershoven C (2020, May 03) A major bull run is forming in oil markets. Retrieved from: https://oilprice.com/Energy/EnergyGeneral/A-Major-Bull-Run-Is-Forming-In-Oil-Markets.html

Wood Mackenzie (2019) Battle for the future: Asia Pacific renewable power competitiveness 2019. Wood Mackenzie. https://www. woodmac.com/reports/power-markets-battle-for-the-future-asiapacific-renewable-power-competitiveness-2019-330243/

World Bank (2019) World Development Indicators. The World Bank

Yasmeen H, Wang Y, Zameer H, Solangi YA (2019) Does oil price volatility influence real sector growth? Empirical evidence from Pakistan. Energy Rep 5:688-703

Zemin J (2008) Reflections on energy issues in China. J Shanghai Jiaotong Univ 3:2 